\title{
Brittle Fracture of Iridium. How This Plastic Metal Cleaves?
}

\author{
Peter Panfilov \\ Institute of Natural Sciences and Mathematics, Ural Federal University, Lenin Av. 51, Yekaterinburg, 620000, Russia
}

Received: October 28, 2019

\begin{abstract}
The refractory platinum group metal iridium is the unique material, insomuch as it exhibits simultaneously two controversial mechanical properties such as the high plasticity and the inclination to the brittle transcrystalline fracture. Although iridium has the face-centered cubic lattice, it meets some empirical cleavage criteria despite considerable plasticity. This is the so called "iridium problem" and it is not solved until now. The review is aimed to the discussion of the experimental data concerning the deformation behavior of iridium and the crack growth in iridium single crystals on the microscopic (in the single crystalline samples stretched on air) and nano- (in the thin foils for transmission electron microscopy) levels. It is shown that cracks in iridium thin foils grow like a crack in such ductile metals as aluminum, copper, and nickel. Cracks in the bulk iridium single crystals behave like either a brittle trancrystalline crack, when the resource of crystal plasticity has been exhausted, or a notch in ductile metal, when the plastic deformation of the sample is possible.
\end{abstract}

\section{INTRODUCTION}

The concept that brittleness and ductility are the polar tendencies in deformation behavior of a solid is the cornerstone of the mechanics of materials [1]. According to the empirical knowledge, a plastic metallic crystal never fails by a brittle manner in an inert environment and, vice versa, a brittle crystal never exhibits an ability to plastic deformation at the macroscopic scale in an inert environment [2,3]. However, the sole refractory face centered cubic (FCC) metal iridium from the platinum group, which cleaves after considerable elongation, is the exception from this rule [4,5]. Iridium possesses unique lattice properties, such as the large values of shear and bulk modulus [6,7] and a negative Cauchypressure [8] that distinct it from other FCC-metals. On the other hand, under compression it behaves like a normal FCC-metal [9]. In addition, iridium meets some empirical cleavage criteria [9-11], and, according to the Rice's approach, the inclination to cleavage is its intrinsic property [12]. In spite of this, another basic characteristic of iridium, namely, the dominant deformation mechanism (it is the octahedral slip (OS) of $<110\rangle$ perfect dislocations) is the same as in a normal FCC-metal $[13,14]$. Therefore, iridium may be formally determined as the plastic cleavable FCC-metal. This circumstance makes it the most puzzling metal in the Earth, while the cause of its anomaly continues to be unclear until now. Such special situation may be explained by the small quantity of researches on deformation behavior and defect structure of iridium, the total list of which is limited by few dozens items $[15,16]$.

It is well-known that fracture mechanisms of a solid can be examined with a help of the analysis of a crack growth [3]. Lynch was the first who studied the cracks advanced in bulk iridium single crystals under bending by metallography. He has shown that extensive plasticity due to OS accompanies a cleavage crack growth $[17,18]$. This result may be estimated as the indirect confirmation of the idea that the mode of crack growth (brittle or ductile) in a metallic crystal depends on dislocation activity at the crack tip [19-22]. However, no experimental data on motion of dislocations near crack tip in

Corresponding author: Peter Panfilov, e-mail: peter.panfilov@urfu.ru

(C) ITMO University, 2019 
iridium were presented in his work [23]. The study of cracks in iridium and aluminum thin foils by transmission electron microscopy (TEM) which was carried out in $[24,25]$ did not reveal the principal differences between them at least at the final stage of crack evolution, but pointed to an opportunity for TEM study of dislocation activity near crack tips in iridium thin foil. Therefore, the main goal of this work is the examination of the crack evolution in single-crystalline iridium on the microscopic scale (in the bulk single crystals under tension) and on the nano scale (in thin foils by TEM) in comparison with other FCC-metals. In addition, the brief review of the mechanical properties of iridium is included in the paper, because it is necessary for the better understanding of the material by a reader. These findings and their discussion could allow better understanding of the nature of the cleavage fracture in iridium and the difference between its deformation behavior and behavior of a normal FCC-metal.

\section{REFINING OF IRIDIUM AND SINGLE CRYSTALLINE SAMPLES FOR STUDY}

Iridium is used as a container material for exploitation under extremely hard conditions, for example, in crucibles for the oxide crystals growing for power lasers or containers for plutonium based eutectics in thermoelectric generators for deep space missions [26-29]. Refining of iridium is the very complicated procedure and, therefore, the technology for its processing was elaborated at the end of 50th years of the XX century by the last among other metals used in industry [15]. The historical aspects of melting and fabrication of iridium were considered in [28], while the modern state of the problem was described in [16] and reviewed recently by Ohriner [30]. The technology for iridium refining based on the "wet" chemical scheme was briefly described in [31], while pyrometallurgical technology including oxidative melting in periclase magnesia crucible and electron beam melting was discussed in [15]. The second technology allows obtaining the high pure plastic iridium during the short time in comparison with the wet chemical refining. The growing of massive single crystals was the final stage of the pyrometallurgical technology. These "single crystalline" ingots were applied as workpieces for processing iridium. In addition, they were used for examination of the mechanical properties of iridium including deformation and fracture mechanisms $[15,16]$.

The high pure iridium from well-known manufacturers was used in the experimental work by every research team who had a deal with iridium. In our case, the Yekaterinburg Non-Ferrous Metal Processing Plant that used the pyrometallurgical scheme for iridium refining [15], supplied the metal for experiments. The massive iridium single crystals (20-50 mm in diameter and 100$150 \mathrm{~mm}$ in length) were grown by means of the zone melting by the electron beam from the ingots of the high pure iridium (99.9\%, non-metallic impurity-free metal). The samples for experiments in the form of the bars with the size of $(15-20) \times 2 \times(0.5-1) \mathrm{mm}^{3}$ were cut from the massive single crystals by the spark erosion technique. They had the following crystallographic orientations: soft $<110>$, hard $<100>$ and octahedral $<111>$ on $\{100\}$ and $\{110\}$ crystallographic planes. Their working surfaces were mechanically abraded and polished in the water solution of $\mathrm{CaCl}_{2}$ or $\mathrm{NaCl}$ in $\mathrm{AC}$. The tensile testing and 3 -points bending of the samples were carried out at the room temperature (the traverse rate was $1 \mathrm{~mm} / \mathrm{min}$ ). The working surfaces of the samples including every crack on the surface were documented with the help of an optical microscope prior and after of each testing. The analysis of obtained images of cracks allowed reconstructing the evolution of transcrystalline cracks on the back surface of iridium single crystals under tension. On the contrary, the crack growth under bending was documented on every step of deformation.

The single crystalline work-pieces, whose surfaces were parallel either cubic $\{100\}$ or $\{110\}$ planes, were mechanically thinned up to the thickness of $0.1 \mathrm{~mm}$. Thin foils for TEM study were prepared by the "window" technique in the jet of an electrolyte. The single crystalline work-pieces were put between tantalum plates with the holes, whose diameter for initial polishing was $1 \mathrm{~mm}$, while for the final thinning it was $2 \mathrm{~mm}$. The water solution of $\mathrm{CaCl}_{2}$ was used as the electrolyte [32]. Iridium plate was used as the second electrode. Preliminary polishing was carried out at 15-18 V AC, while the final stage of polishing was carried out at 5-10 V AC. The optimal temperature for electropolishing was $60-80{ }^{\circ} \mathrm{C}$, therefore, no cooling device was included in the thinning facility. Thin foils contained a lot of pitting holes, where many V-shape cracks appeared, and, therefore, no special procedure for inflicting the cracks to the sample was required. Both tension and bending of the foils in the air caused the increase of the number of cracks, but no appearance of the dangerous cracks was revealed here. It was impossible to observe the propagation of selected crack because of its small size and irregular distribution of deformation in the foil under tension in TEM facility. Therefore, the evolution of cracks in iridium thin foils was reconstructed with a help of analysis of the images of cracks having the lengths from the nano-scale $(\sim 10 \mathrm{~nm})$ up to $0.5 \mu \mathrm{m}$. On the contrary, the forming of dangerous cracks and their propagation in the foil were study during in situ tensile testing in the column of $200 \mathrm{kV}$ TEM facility. 


\section{DEFORMATION BEHAVIOR OF IRIDIUM}

The first communication reporting that iridium was successfully processed appeared in 1958 [26]. The next information on the deformation behavior of polycrystalline iridium (samples with a rectangle cross-section) under tension at $20-2000{ }^{\circ} \mathrm{C}$ was published in [33]. Yield stress and ultimate tensile strength (both are $\sim 1000 \mathrm{MPa}$ at 20 ${ }^{\circ} \mathrm{C}$ ) drop sharply down to $140 \mathrm{MPa}$ and $200 \mathrm{MPa}$ at 1300 ${ }^{\circ} \mathrm{C}$. After that, the rate of their decrease became considerably slower: $30 \mathrm{MPa}$ and $75 \mathrm{MPa}$ at $2000^{\circ} \mathrm{C}$. On the contrary, the elongation prior the failure continues to be constant and small until $1000^{\circ} \mathrm{C}(\sim 1.5 \%)$. It begins increasing rapidly up to $10 \%$ at $1500^{\circ} \mathrm{C}$, while further it drops smoothly up to $8 \%$ in the temperature range 1500 $2000{ }^{\circ} \mathrm{C}$. According to metallographic examination, no necking was observed on the samples, while their fracture mode was attested as the brittle intergranular fracture (BIF) at $T<900^{\circ} \mathrm{C}$ and $T>1600^{\circ} \mathrm{C}$ with some addition of the brittle transgranular fracture (BTF) at temperatures $900-1600^{\circ} \mathrm{C}$. The authors suppose that segregation of impurities on grain boundaries is the cause of the poor deformability of the iridium samples. These results were confirmed by the research team from USA, whose wire samples demonstrated the same tensile strength, while their plasticity was close to a normal FCC-metal at comparable homological temperatures [34]. The fracture mode of the samples was determined as BIF. The similar values of the tensile strength, but the smaller elongation were obtained for the polycrystalline samples with a circle cross-section in [35]. It was shown that the localization of plastic deformation in the neck increases sharply when iridium samples are coated by a thin layer of platinum. The data obtained by the team from ORNL [36] for the plane polycrystalline iridium samples with the double-spoon shape under tension were close to the results reported in [34].

Tensile testing of non-annealed thin iridium wires ( $0.3 \mathrm{~mm}$ in diameter) at $20-1600^{\circ} \mathrm{C}$ showed that the total elongation of the samples decreased smoothly with the temperature rising from $\sim 10 \%$ at $20^{\circ} \mathrm{C}$ up to $5 \%$ at $800^{\circ} \mathrm{C}$ because of the considerable localization of plastic deformation in the neck [37]. Recent room temperature tensile testing of the non-annealed iridium wire $(0.5 \mathrm{~mm}$ in diameter) has confirmed that it exhibits considerable elongation and necking ( $30 \%$ and $\sim 23 \%$, respectively), despite BTF as the fracture mode (Fig. 1). Further slow growth of the elongation up to the value of room temperature deformation $(\sim 10 \%)$, which occurs at more high temperatures $\left(>1000^{\circ} \mathrm{C}\right)$ when the iridium recrystallization starts, is caused by both "necking to a point" and "flowing neck" effects. In spite of this, the fracture mode of the wires was determined as BTF until the moment when

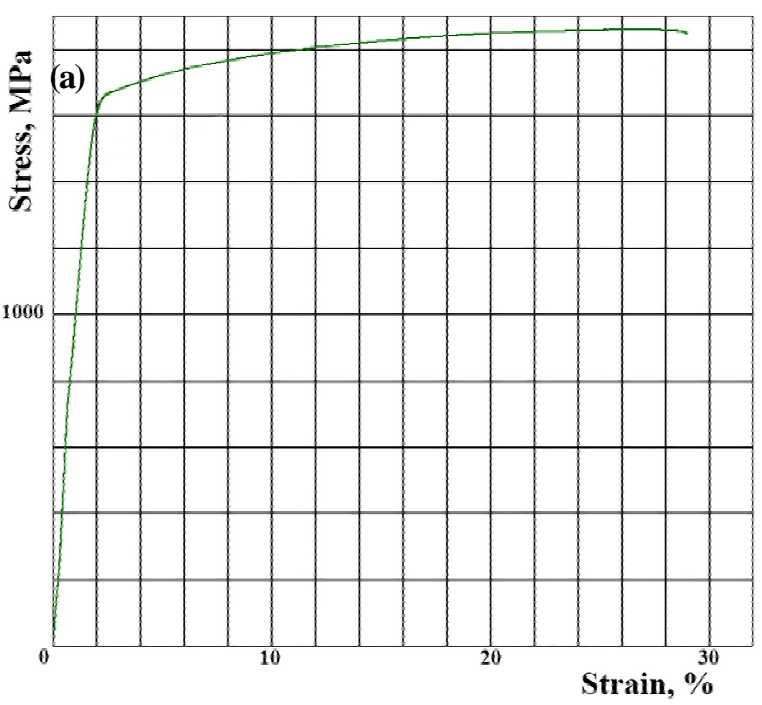

(b)

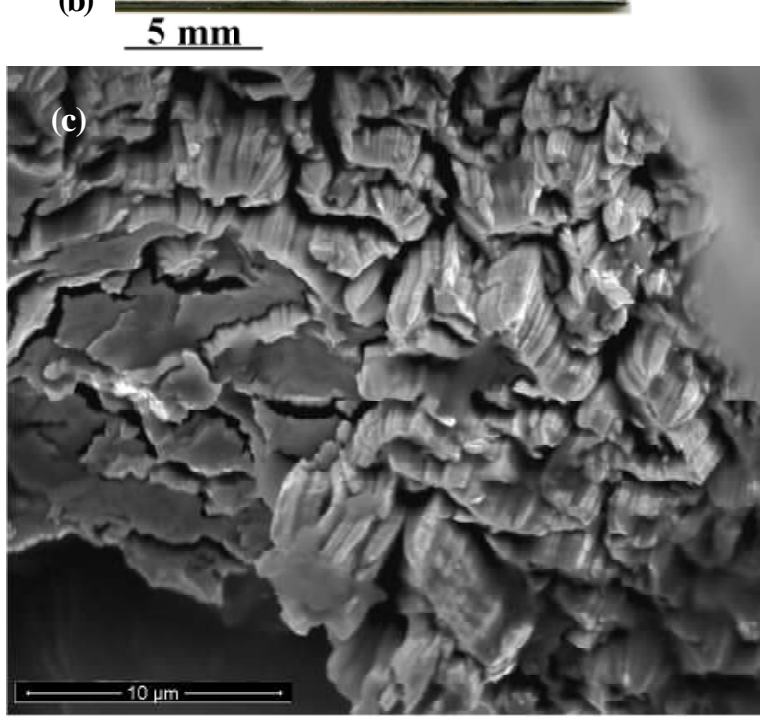

Fig. 1. Deformation behavior of iridium wire under tension at room temperature: a - stress-strain curve; b: the back surface of sample after tension (elongation 29\%, necking 23\%); c - fracture surface of the sample (BTF).

the necking to a point appears and, hence, the fracture surface of sample transforms into a topographic point. It was shown that BTF is the intrinsic fracture mode of iridium, while BIF is caused by the dangerous non-metallic impurities, such as carbon and oxygen [38]. Therefore, it may be concluded that the deformation behavior of polycrystalline iridium is similar to a normal FCC-metal excepting the fracture mode.

The study of the mechanical behavior of metallic single crystal in dependence on its crystallography allows determining the deformation mechanisms that are active in this metal [2]. The first information on mechanical properties of single crystalline iridium contradicted with the empirical knowledge on a FCC-metal: at room temperature, it cleaves after elongation more than $10 \%$ [4]. Detailed study [5] confirmed that iridium single crys- 

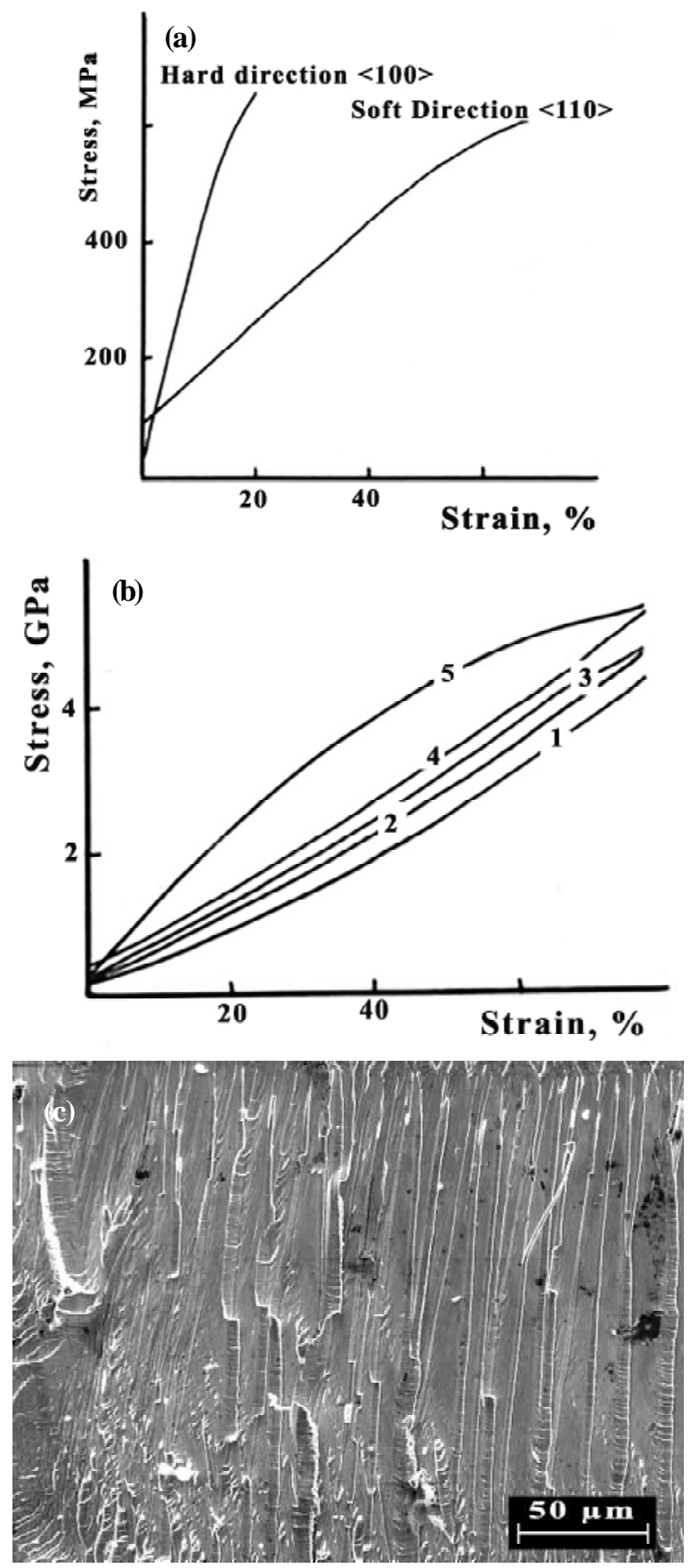

Fig. 2. Deformation behavior of iridium single crystals at room temperature: a - stress-strain curves under tension ( 1 - <100> axis, 2 - <110> axis, - soft direction); b: stress-strain curves under compression $(1-<100>$ axis, 2 - <110> axis, 3 - severe deformed single crystal, 4 $<110>$ axis $\operatorname{Ir} 3 \operatorname{Re} 2 \mathrm{Ru}, 5-<110>$ axis $\operatorname{Ir} 0.3 \mathrm{~W})$; d - fracture surface of the sample (BTF).

tals cleave after the huge elongation without necking $\left(80 \%\right.$ at $20^{\circ} \mathrm{C}$ and $100 \%$ at $100^{\circ} \mathrm{C}$ ) [5]. The intrigue was reinforced by the finding that single crystalline iridium under compression behaves like a normal FCC-metal (copper), which is deformed due to octahedral slip and never fails $[9,39,40]$. Mechanical behavior of iridium sin- gle crystals under tension and compression was examined at room temperature on the samples having soft and hard orientations $(<100>\{100\}$ and $<110>\{100\}$, $<110\}<110>$ ). It was shown that the strong orientation anisotropy takes place in iridium single crystals: yield stress and elongation prior the failure for the soft direction were $100 \mathrm{MPa}$ and $20 \%$, respectively; these parameters for the hard direction were $10 \mathrm{MPa}$ and $40 \%$, while the ultimate tensile strength was about $600 \mathrm{MPa}$ for both cases (see Fig. 2a) [41]. Analysis of the shape of the stress-strain curves allows concluding that whole considerable plasticity of the single crystalline iridium is reached on the first stage of the plastic deformation [2]. On the contrary, no clearly visible orientation anisotropy was revealed in iridium single crystals under compression (Fig. 2b). In spite of considerable plasticity under tension, the fracture mode of the samples was attested as BTF [24] (Fig. 2c). Under compression, iridium single crystals exhibited the huge plasticity (up to $80 \%$ ) and never failed under loading [41].

Deformation tracks appeared on the back surface of iridium single crystals under tension were examined in [14]. According to geometry of the deformation tracks and their distribution on the working surfaces of the samples under tension, at room temperature single crystalline iridium is deformed due to the octahedral slip, at that, whole plasticity of the single crystal is realized on the easy slip stage (Fig. 3). As a result, the necking never occurs in the single crystalline samples despite that their elongation could reach $60-70 \%$. TEM study has shown that straight dislocation segments having Burgers vector laid along <110> are the main feature of defect structure in iridium single crystals at room temperature (Fig. 4). There are not small angle boundaries despite of the high density of $\langle 110\rangle$ dislocations in deformed single crystalline thin foils. It means that cellular / grain structure is not formed in iridium single crystal during the room temperature deformation. No motion of dislocations was revealed by TEM during in situ tension in a column. These facts may be explained by the supposition on the low mobility of $\langle 110\rangle$ dislocations in iridium at room temperature. On the other hand, small angle boundaries and pileups of curvilinear dislocations are the dominant morphological features of defect structure in the polycrystalline iridium, while straight dislocations are absent here (Fig. 5) [42]. Hence, dislocation structure in iridium develops by the same way as in a usual FCC-metal if the grain structure is formed in the sample, while its development is frozen on the easy slip stage in the case of tension of the single crystalline sample at room temperature [14].

Obtained results could be summarized as follows. At room temperature, iridium behaves like a normal FCCmetal, excepting special fracture mode (BTF) and the 

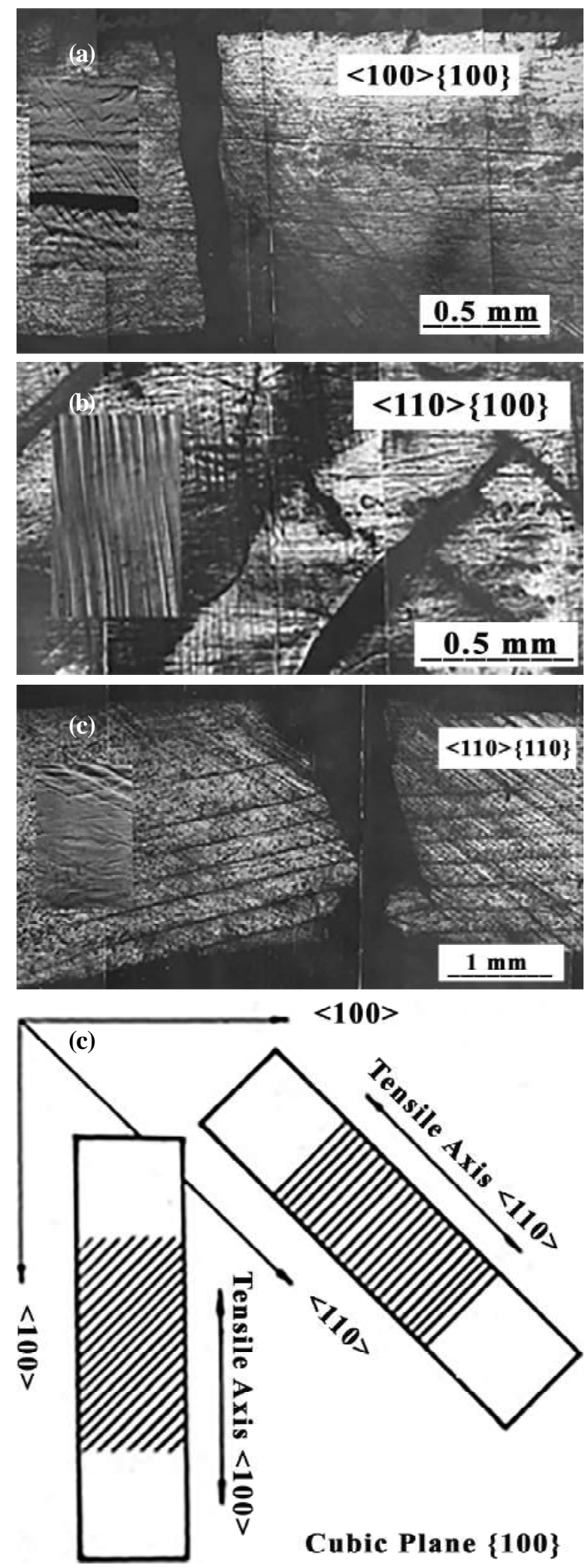

Fig. 3. Defect structure of iridium single crystals after tensile testing (microscopic scale): a - slip bands on the $<100>\{100\}$ samples $(\varepsilon \sim 10 \%)$; b - slip bands on the $<110>\{100\}(\varepsilon \sim 40 \%) ; c-$ slip bands on the $<110>\{110\}$ ( $\varepsilon \sim 30 \%$ ); d-crystallography of the octahedral slip.

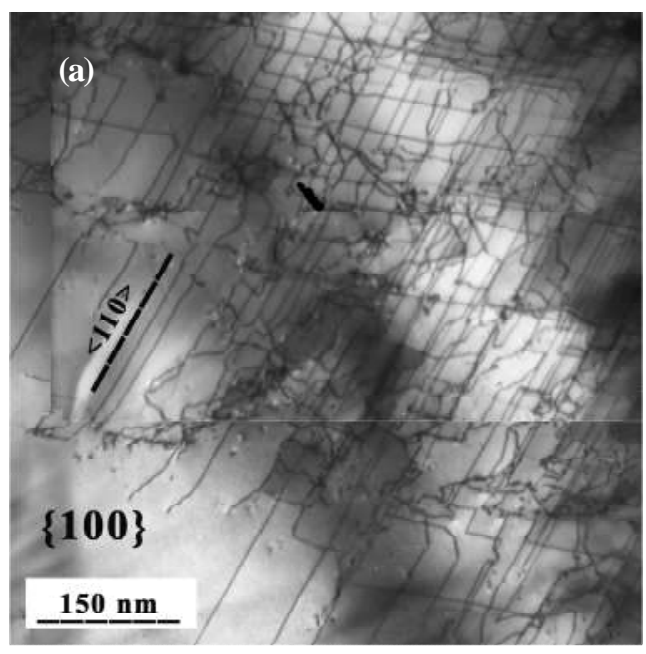

Fig. 4. Defect structure of iridium single crystals after tensile testing (nano-scale).

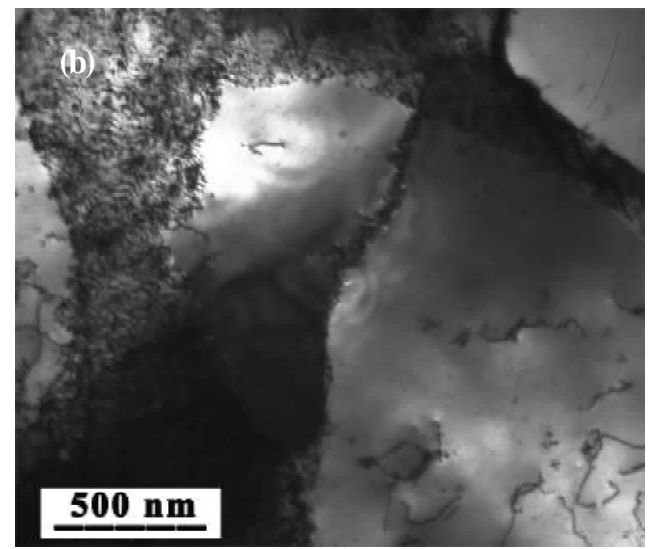

Fig. 5. Defect structure of polycrystalline iridium (nanoscale).

feature that takes place in iridium single crystals under tension. Taking into account that iridium is the sole refractory FCC-metal in the Earth, these distinctions are not contradictions with the empirical knowledge on a FCC-metal, because the room temperature for iridium is the very low (almost helium) temperature on the homological scale.

\section{EVOLUTION OF CRACKS IN BULK IRIDIUM SINGLE CRYSTALS}

The study of cracks on the bulk iridium single crystals was carried out on the samples that demonstrated elongations from $10 \%$ up to $40 \%$. Metallographic attestation has shown that all cracks were situated on the edges of the samples. They appeared on the surface after elongation of 3-5\%, whereas the samples failed after $10-20 \%$ and $30-40 \%$ for the hard orientation and the soft orientation, respectively. Cracks in the $<100>\{100\}$ crystals had a straight profile, a sharp tip, 

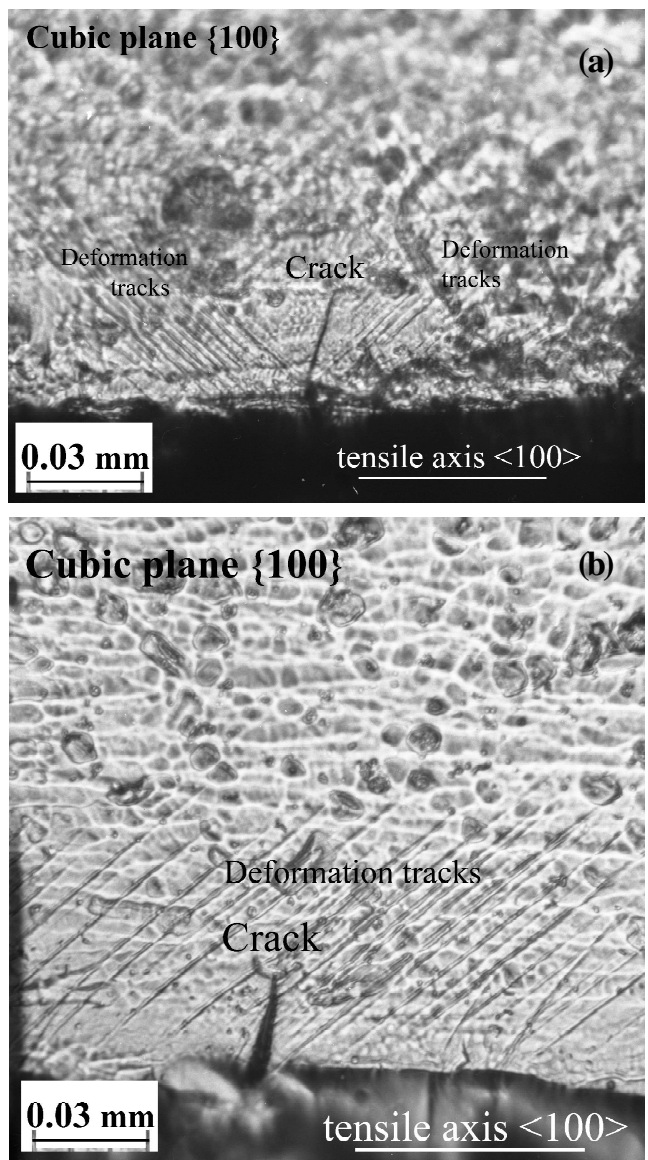

Fig. 6. Tiny cracks having a length of $\sim 0.03 \mathrm{~mm}$ in $<100>\{100\}$ iridium single crystal: a - the crack with $\mathrm{ACO}<1^{\circ} ; \mathrm{b}-$ the crack with $\mathrm{ACO} \sim 10^{\circ}$.

and were perpendicularly directed to the tensile axis of sample. The length of the cracks started from $0.03 \mathrm{~mm}$. Therefore, $0.03 \mathrm{~mm}$ cracks may be denoted as the smallest cracks in the iridium single crystals. No deformation tracks were observed near their coasts. There were two sets of the tiny cracks on the $<100>\{100\}$ single crystals. The minor part of them $(\sim 1 / 10)$ possessed the angle of crack opening (ACO) less than $1^{\circ}$ (Fig. 6a), while the majority of them had ACO $10-15^{\circ}$ (Fig. 6b). The cracks from the next set had the length of $0.06 \mathrm{~mm}$ and laid perpendicularly to the tensile axis of the samples. They were the majority of cracks in the iridium single crystals under tension. Some of them consisted of the two parts having the different shapes: the bottom one had 0.03 $\mathrm{mm}$ in length and $\mathrm{ACO} \sim 10^{\circ}-15^{\circ}$, while the upper one possessed the same length, but its ACO was $\sim 1^{\circ}$ (Fig. 7a). Deformation tracks, whose geometry is close to the octahedral slip on $\langle 100\rangle\{100\}$ of the FCC lattice, were observed near the bottom parts of such cracks only. Metallographic analysis of other cracks has shown that they also consisted of two parts having the equal lengths, but their upper parts had ACO 10-15 ${ }^{\circ}$ and deformation tracks were observed along all crack coasts
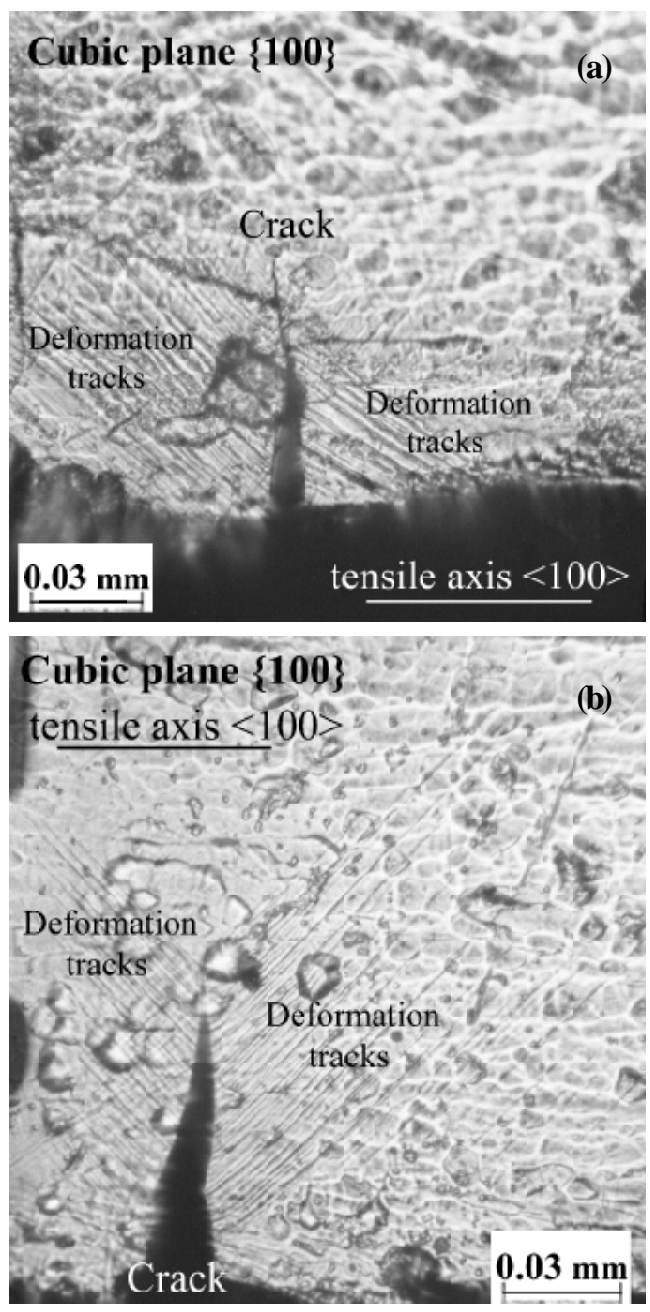

Fig. 7. Cracks having a length of $0.06 \mathrm{~mm}$ in $\langle 100\rangle\{100\}$ iridium single crystal: $\mathrm{a}-0.03 \mathrm{~mm}$ crack with $\mathrm{ACO} \sim 1^{\circ}$ at $0.03 \mathrm{~mm}$ crack with $\mathrm{ACO} \sim 10^{\circ} ; \mathrm{b}-\operatorname{crack}\left(\mathrm{ACO} \sim 10^{\circ}\right)$ and deformation tracks leaving its coasts.

(Fig. 7b). Hence, ACO was changing in the process of crack evolution under tension. The long cracks having the length, which may be expressed as $n \times 0.03 \mathrm{~mm}(n=3$, 4,5 , etc.), were detected in the samples after tensile tests, but their quantity was considerably lower than the number of $0.06 \mathrm{~mm}$ cracks ( $<10$ pieces and 30-40 ones per sample, respectively). The shape of such cracks including ACO and their trajectories continued to be the same. Deformation tracks, whose geometry agreed with the octahedral slip distribution, were also observed in vicinity of the cracks (Fig. 8a). However, they never occurred near the upper part of the dangerous cracks, whose motion causes the separation of sample, whereas the deformation tracks were detected in their bottom part (Fig. 8b).

The mechanistic picture of the cracking in iridium single crystals, which were stretched along the soft $<110>$ direction, had many common features with the case described above. The first, cracks possessed a 


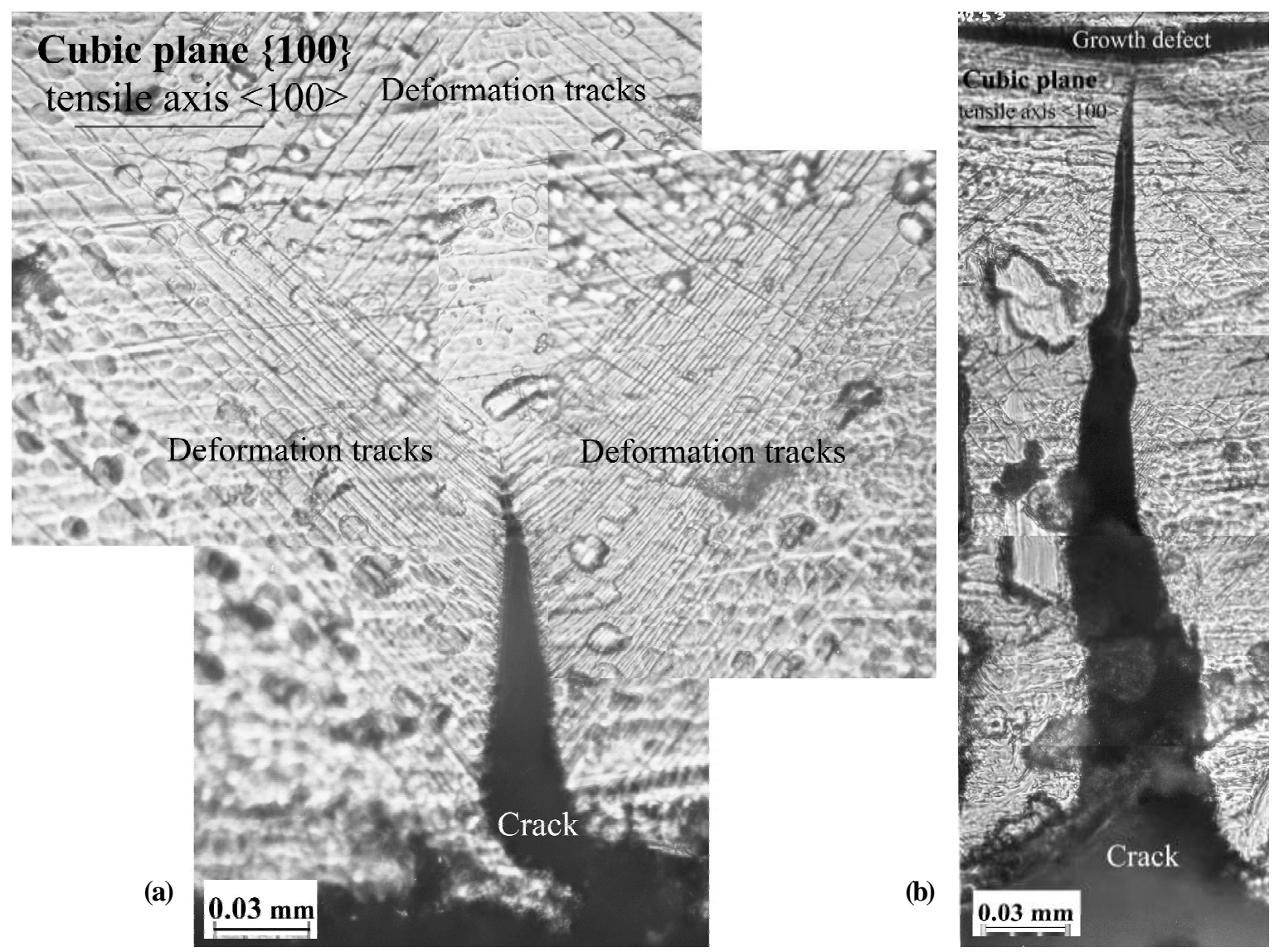

Fig. 8. Long cracks in $<100>\{100\}$ iridium single crystal: a - crack having the length $\sim 0.15 \mathrm{~mm}$ and $\mathrm{ACO} \sim 10-15^{\circ}$ with deformation tracks; $\mathrm{b}$ - dangerous crack (length $\sim 0.30 \mathrm{~mm}, \mathrm{ACO} \sim 10^{\circ}$ ).
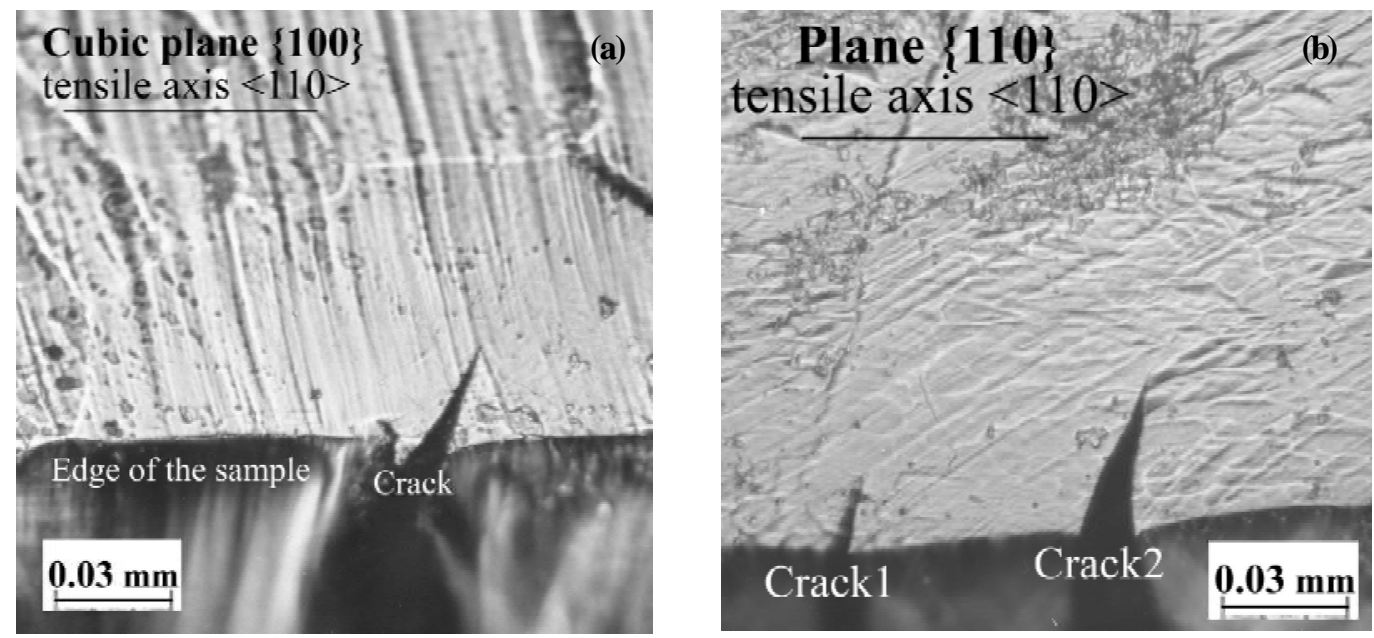

Fig. 9. Cracks in iridium single crystals having $<110>$ tensile axis: a - tiny crack with the length of $\sim 0.03 \mathrm{~mm}$ and ACO $\sim 10-15^{\circ}$ in $<110>\{100\}$ iridium single crystal; $b$ - tiny cracks with the length of $\sim 0.03 \mathrm{~mm}$ and ACO $\sim 10 \div 15^{\circ}$ in $<110>\{110\}$ iridium single crystal; $\mathrm{c}-$ cracks having a length of $\sim 0.06 \mathrm{~mm}$ in $<110>\{100\}$ iridium single crystal (ACO $\sim 10-15^{\circ}$ ) with $0.03 \mathrm{~mm}$ satellite crack.

straight profile and a sharp tip with $\mathrm{ACO} \sim 10-15^{\circ}$ (Fig. 9a). The second, there was the minimal size of the cracks in the $\langle 110\rangle$ iridium single crystals (it is also $0.03 \mathrm{~mm}$ ). The third, no deformation tracks were observed near the coasts of the smallest cracks. The fourth, deformation tracks, whose geometry agreed with the distribu- tion of octahedral slip bands in the deformed $\langle 110\rangle$ iridium single crystals [14], were observed near $n \times 0.03 \mathrm{~mm}$ ( $n=3,4,5$, etc.) cracks (Figs. 9b and Fig. 10a). However, some distinctions exist, too. Cracks were inclined to the tensile axes under angles $60^{\circ}$ and $70^{\circ}$ for $\langle 110\rangle\{100\}$ and $\langle 110\rangle\{110\}$ crystals, respectively. Deformation 

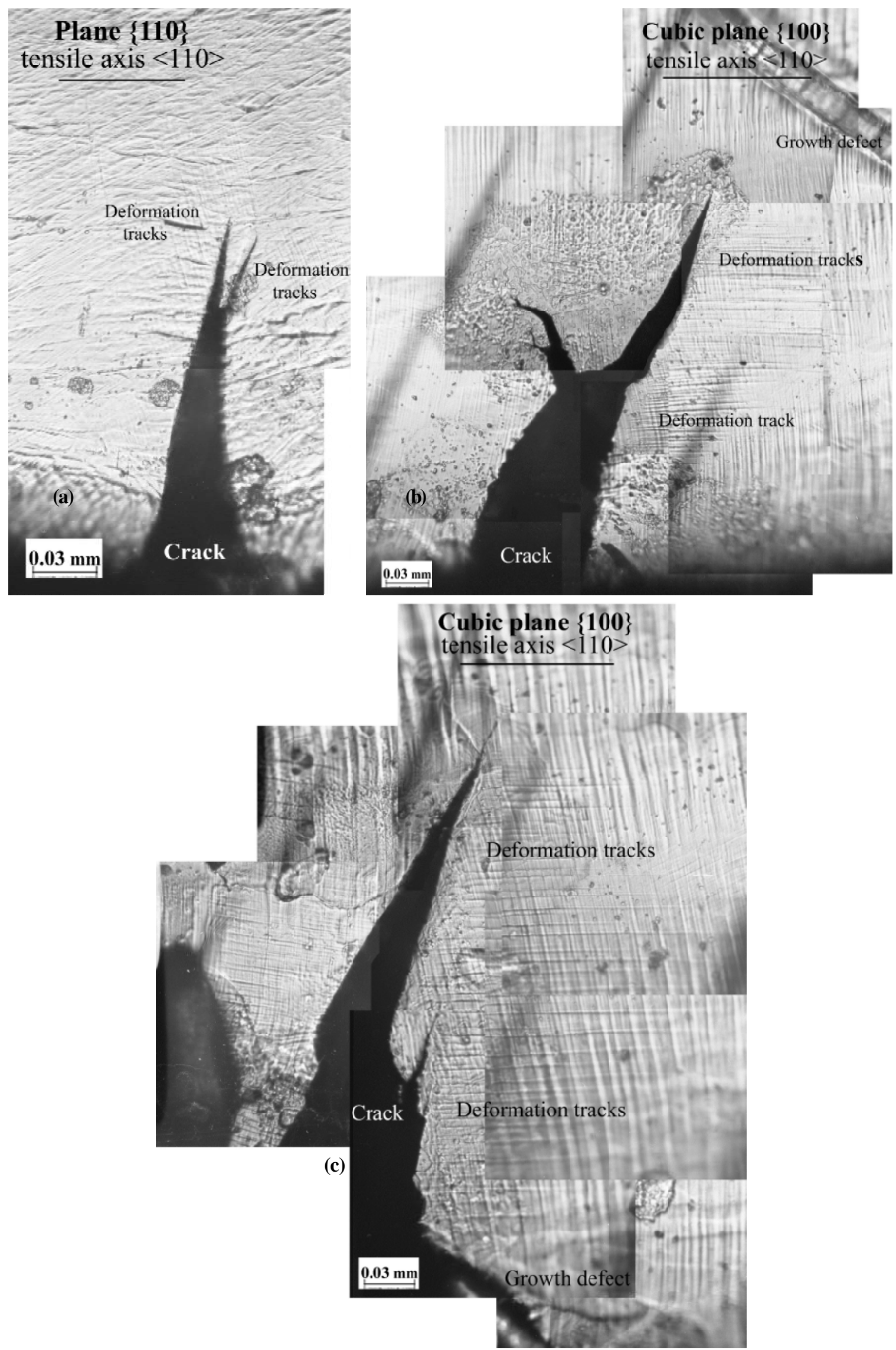

Fig. 10. Dangerous cracks in the iridium single crystals having $<110>$ tensile axis: a -dangerous crack with branched tip in $<110>\{110\}$ iridium single crystal; $b-$ satellite crack accompanies the dangerous crack in $<110>\{100\}$ iridium single crystal; $c$ - dangerous crack without the branching in $<110>\{100\}$ iridium single crystal. 

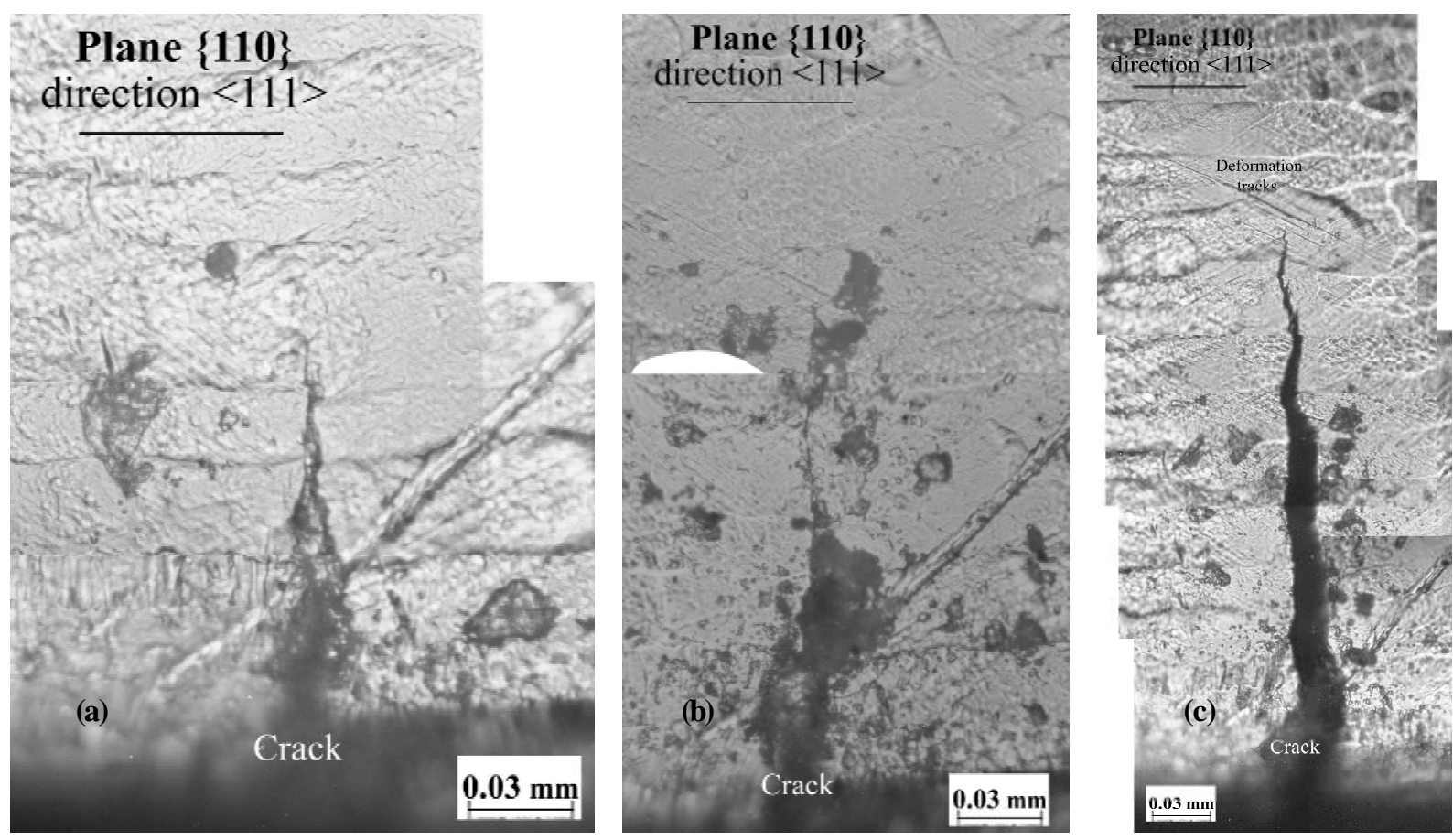

Fig. 11. Crack growth in the iridium single crystalline sample having $<111>\{110\}$ orientation under bending: $a-$ bend $1 ; \mathrm{b}-$ bend $2 ; \mathrm{c}-$ bend 3 (the dangerous crack).

tracks occurred near the single coast only. The next specific feature of the cracks in $\langle 110\rangle$ iridium single crystals was the satellite cracks, which appeared near/in vicinity of the main cracks (Figs. 9a-9c and Figs. 10a-10c). Crystallographic analysis of crack geometry has shown that cleavage is advancing on $\{210\}$ plane, which is the secondary cleavage plane for cubic lattice $[2,43]$. The satellite cracks in $\langle 110\rangle\{100\}$ crystals were the cracks moved on the another $\{210\}$ cleavage plane having unfortunate orientation under applied stress. The branching of crack tips in $\langle 110\rangle\{110\}$ (Fig. 10a) may be connected with an opportunity for crack to advance on another cleavage ( $\{100\})$ plane, too. In this case, the motion on $\{210\}$ is the more preferable than on the cubic plane and, therefore, fracture surface coincides with the secondary cleavage plane. It should be noted that some long cracks have $\mathrm{ACO} \sim 1-2^{\circ}$, despite huge width in their bottom part and deformation tracks near the crack edge as well.

The crack growth in $\langle 111\rangle\{110\}$ iridium single crystal under bending is shown in Figs. 11a-11c, but had the tendency to move perpendicularly to the tensile axis of the sample. ACO was about $1^{\circ}$ during the test. No deformation tracks were detected near the crack edges during $1^{\text {st }}$ and $2^{\text {nd }}$ bends. Deformation tracks appeared in the upper part of the crack and the width of the bottom part of crack enlarged at the final stage of crack growth.

The behavior of notches in aluminum single crystals under tension and bending is shown in Fig. 12 and Fig. 13, respectively (Note that the samples had the same crystallographic orientation). Penetration of the razor blade into the undeformed sample induced an appearance of the octahedral slip bands of the two octahedral systems near the notch. However, only sole slip system was activated in the crystal until 10-15\% of elongation. Plastic deformation was homogeneously distributed on the surface at this stage of stretching. The length of notch did not change, whereas its width extended proportionally to the local deformation of the sample at this place. On the contrary, at least two slip systems operated under bending at the initial stage of deformation. There was deformation relief in the bended samples. The length of notch continued to be the same while its width was changed inconsiderably.

\section{EVOLUTION OF CRACKS IN THIN FOILS OF IRIDIUM SINGLE CRYSTALS}

The smallest crack that was revealed in iridium thin foils is given in Fig. 14a (the plane of foil is $\{100\}$ ). Such cracks were always situated on the edges of foils, where mobile dislocations were absent due to the high level of the surface stress [44]. Their length was about $10 \mathrm{~nm}$, while the width was about $1 \mathrm{~nm}$. The size of this crack can be estimated as few units of interatomic distances in the crystal lattice of iridium. It had the shape of a narrow straight strip that originated at the edge of pitting hole. Its bottom part was colored in white, while the upper part was colored in black. Lamella-like region hav- 

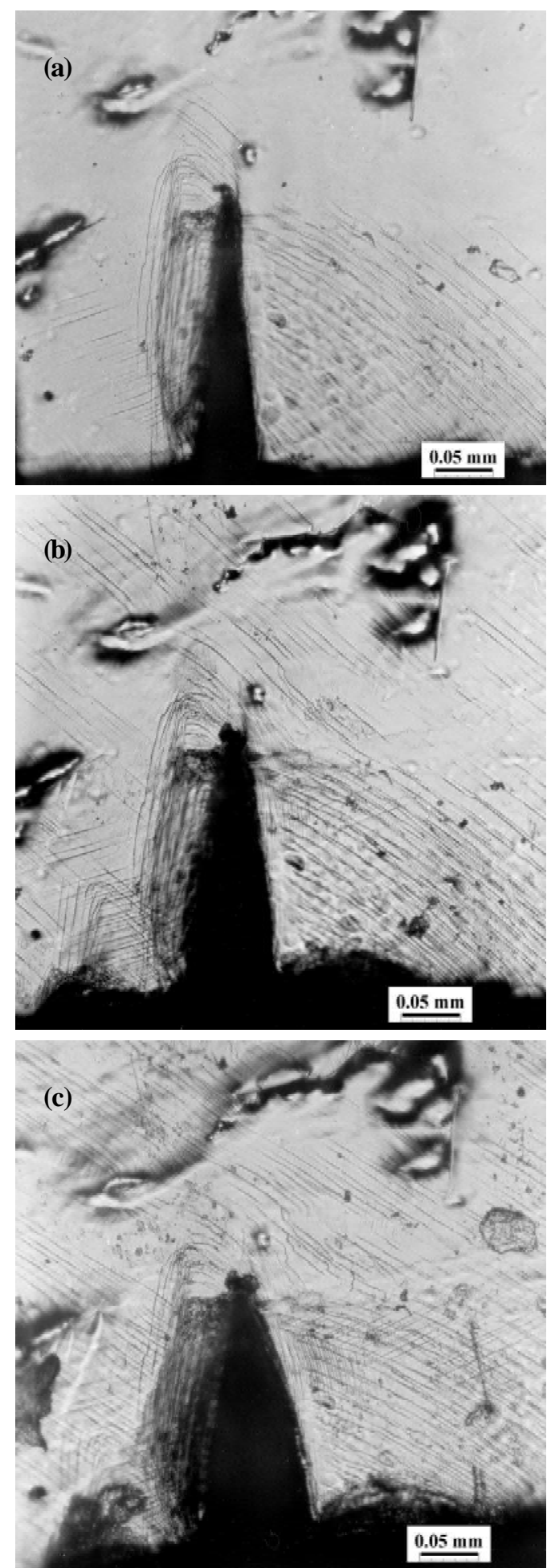

Fig. 12. Evolution of the notch in the aluminum single crystal under tension: $\mathrm{a}$ - undeformed state; $\mathrm{b}-6 \%$ elongation; $\mathrm{c}-12 \%$ elongation.

ing a weak strip black/white (stacking fault) contrast jointed to the crack. The length of the lamella was estimated as $1 \mu \mathrm{m}$ that at least two orders higher than the crack length. In the place of joining with the crack, the lamella possessed the narrow end, whose width was about the width of the upper part of the $\operatorname{crack}(\sim 1 \mathrm{~nm})$,
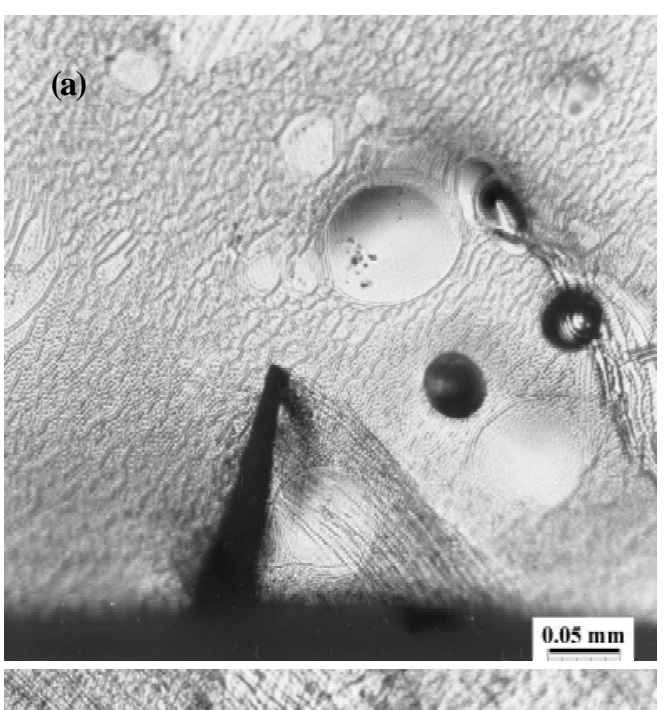

(b)
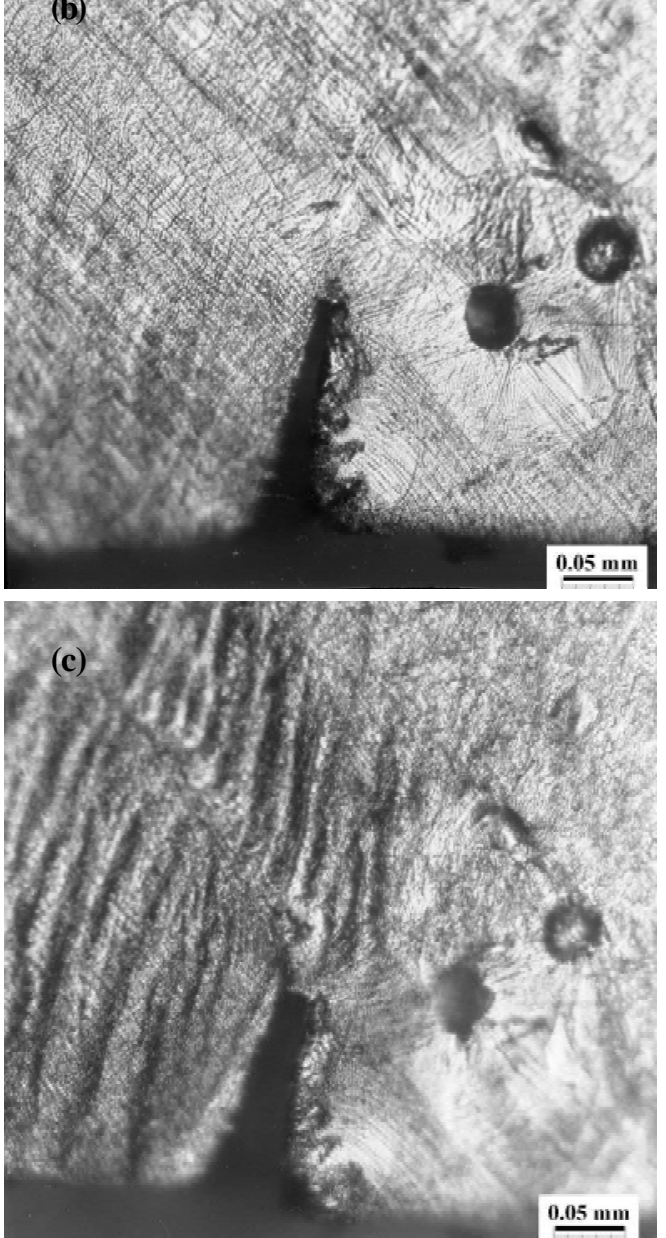

Fig. 13. Evolution of the notch in the aluminum single crystal under bending: $\mathrm{a}-$ undeformed state; $\mathrm{b}-1$ st bend; $\mathrm{c}-4$ th bend.

whereas its opposite end was considerably wider (width $\sim 100 \mathrm{~nm}$ ). Perhaps, the shape of lamella depended on the foil profile, whose thickness is rising from the foil edge to its depth. Sometimes, the objects which look like a single dislocation could be situated inside the lamella (Fig. 14a). 
(a)

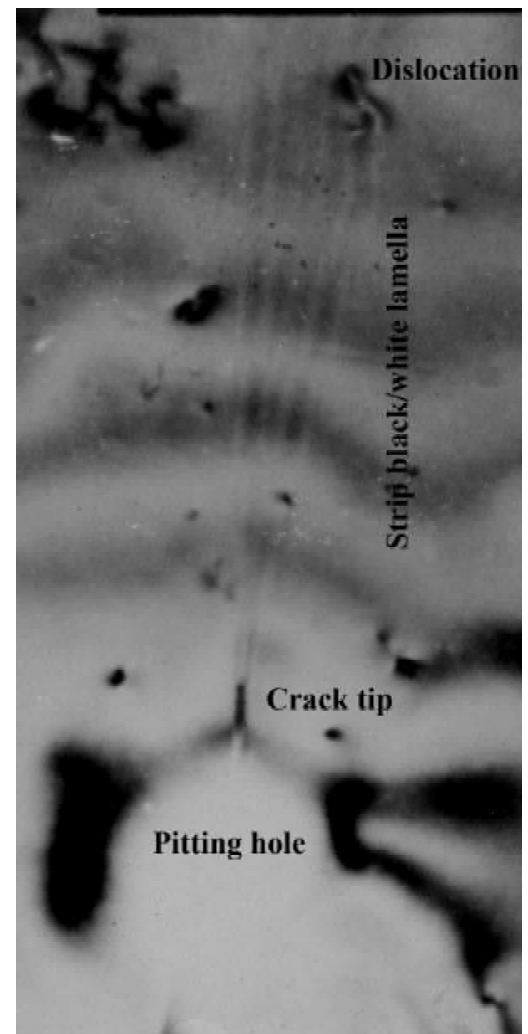

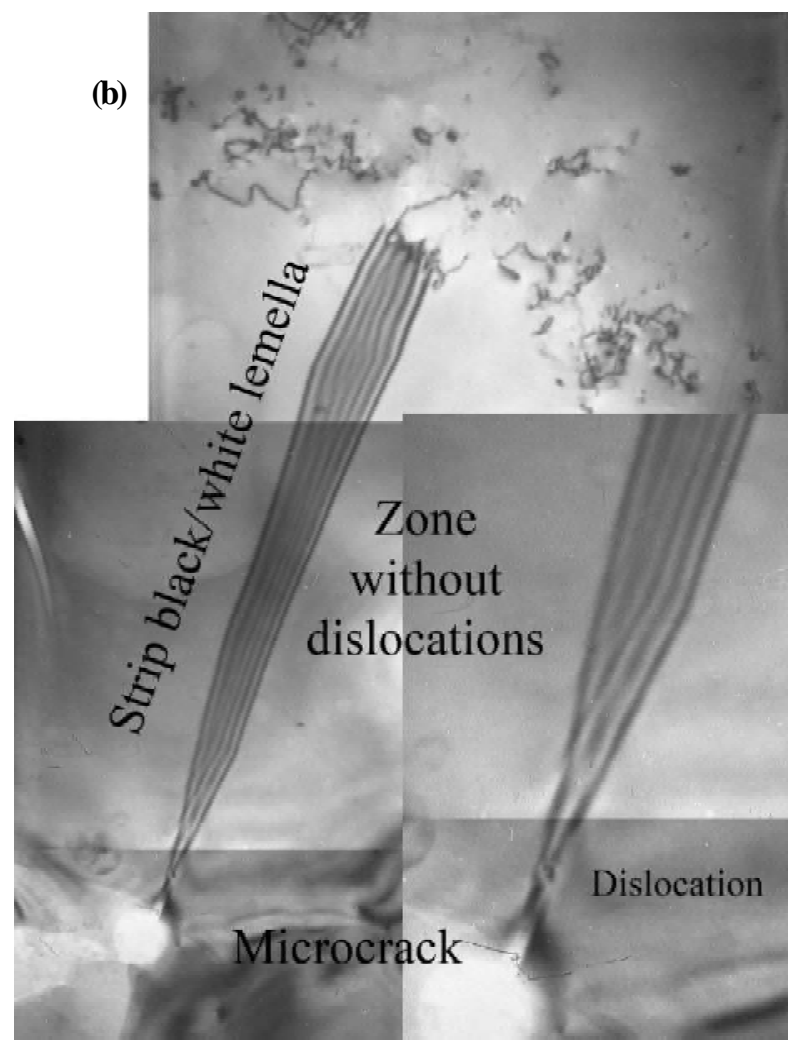

Fig. 14. Cracks with strip black/white lamellas in iridium thin foil: a-atomic or nano-scale crack (length $<0.01 \mu \mathrm{m}$ ), $\mathrm{b}-$ crack length $<0.05 \mu \mathrm{m}$.

The growing of the crack up to $50 \mathrm{~nm}$ led to the increase in the power of the strip contrast in the lamella, but its shape and length $(\sim 1-2 \mu \mathrm{m})$ continued to be the same (Fig. 14b). It should be noted that the lamella was ended at the place, where $\langle 110\rangle$ dislocations began to appear in the foil. The distance between the foil edge and this region, which had been measured far away from cracks, was about 1-2 $\mu \mathrm{m}$. The top and bottom of these cracks were also colored in black and white, respectively. Single dislocations could be observed inside the lamellas, too. No clear visible twin spots were detected on the diffractions taken from lamellas near these nanoscale cracks.

The next step of crack growth up to $\sim 0.1 \mu$ m induced the amplifying of the "black/white" contrast in the lamella (Fig. 15a) and the appearance of twinned spots on the diffraction pattern (the foil plane is $\{110\}$ ). Dark field images taken in the twin reflex have shown that the lamellas are the microtwins (Fig. 15b). It agrees with the information presented in [5] that a crack in iridium thin foils could emit twin lamellas. In spite of this, the length of lamellas continued to be the same $(\sim 1-2 \mu \mathrm{m})$. These $0.1 \mu \mathrm{m}$ cracks had a sharp tip, but complicated shape, which was close to $\mathrm{V}$-shape with the large $\mathrm{ACO} \sim 10-30^{\circ}$ (Fig. 15c). For comparison, cracks in thin foil of silicon had a needle like shape with $\mathrm{ACO} \sim 1^{\circ}$ [45]. The place, where the twin lamella joined to the crack, was not a geometrical point at the crack tip, inasmuch as its longitude on the crack edge was about $50 \mathrm{~nm}$. In addition, according to Fig. $15 \mathrm{c}$ at least two twin lamellas, which had the same crystallographic orientations, were situated near the crack. All microtwins contained dislocations, whose concentration is growing up during promotion from the crack tip (Fig. 15c) to the end of the lamella (Fig. 15d). The same picture occurred in the case when the foil had another crystallographic orientation (the foil plane is $\{100\}$ ): V-shape cracks joined with two twins having the length of $\sim 1-2 \mu \mathrm{m}$ (Fig. 16a). Dislocation pileups, whose density was rising from the crack tip to the opposite end of the microtwin, filled every lamella. Places of contact between crack and twin lamella had a longitude of $\sim 50 \mathrm{~nm}$ too (Fig. 16b). The geometry of cracks may be also estimated as complicate shape having the sharp tip with the considerable ACO. However, in contrast with previous case, each crack joined with two twin lamellas developed in the different crystallographic directions. It is a usual response of the high symmetric FCC lattice, where always exist at least two equivalent directions for mechanical twinning, whereas previous case should be considered as some exception caused by special crystallographic orientation of both thin foil and crack [43].

The growth of crack up to $\sim 0.2-0.3 \mu \mathrm{m}$ led to the increasing of visible quantity of dislocations in the 

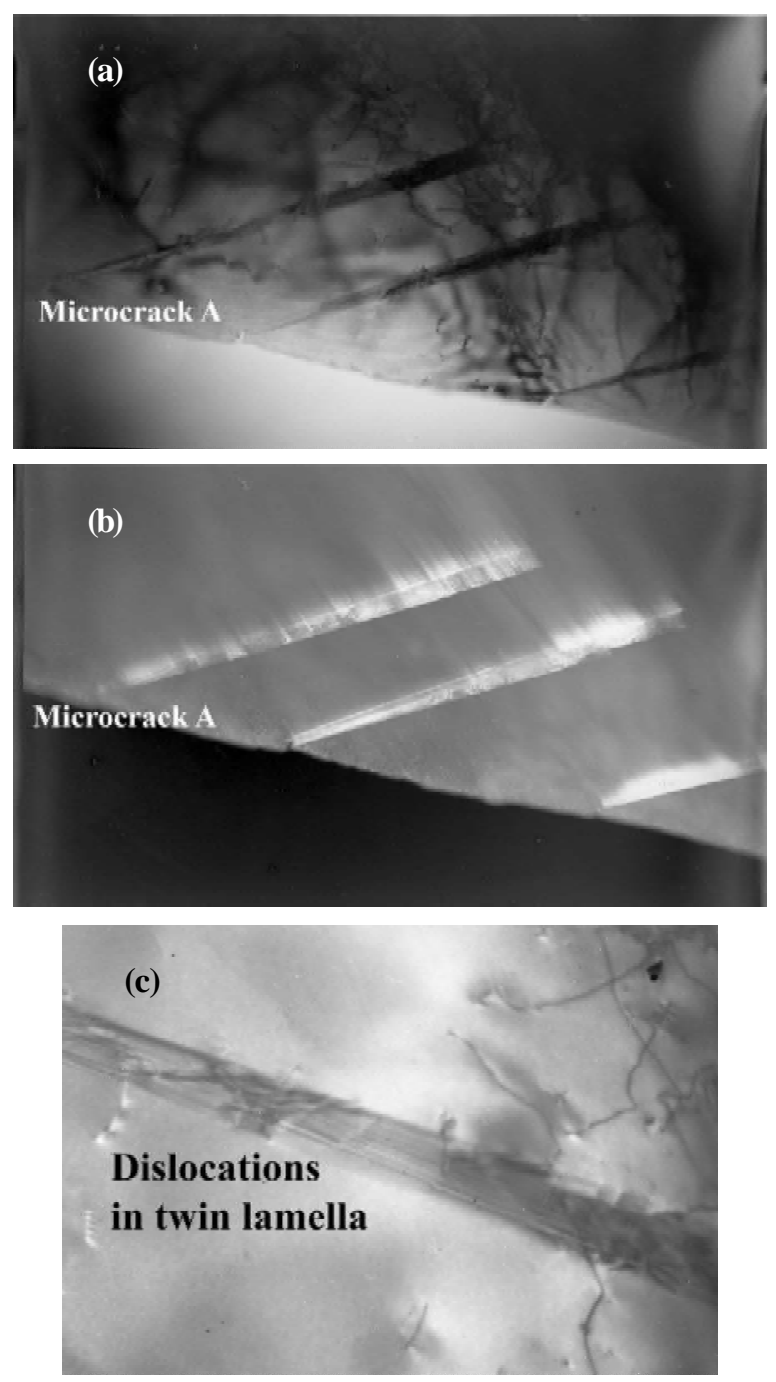

(a)

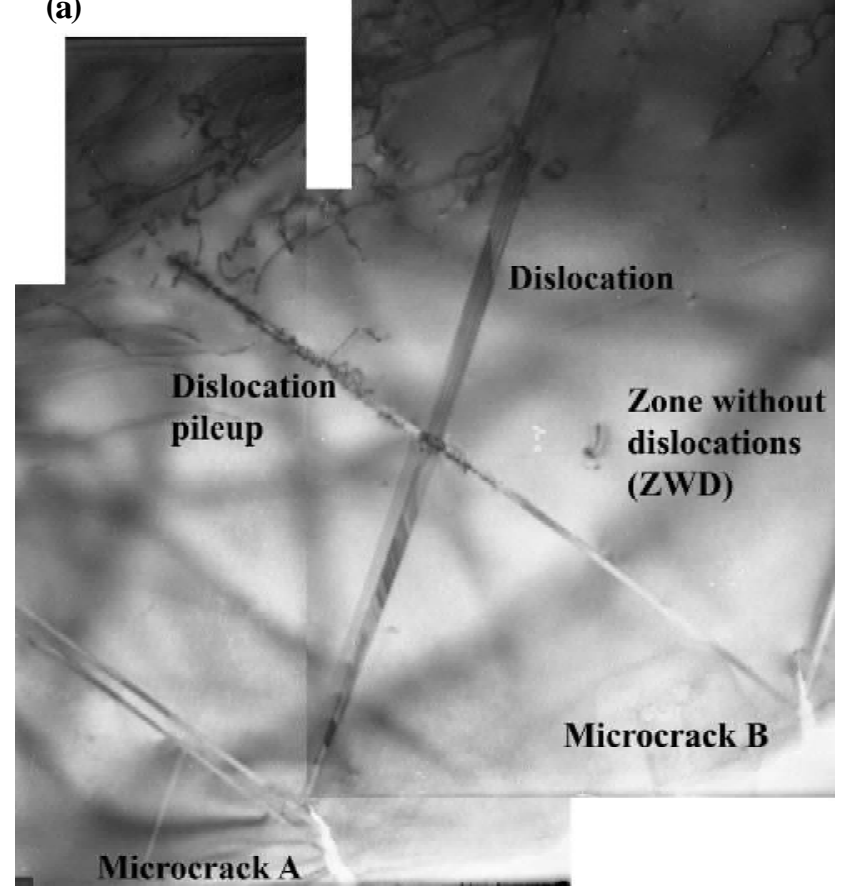

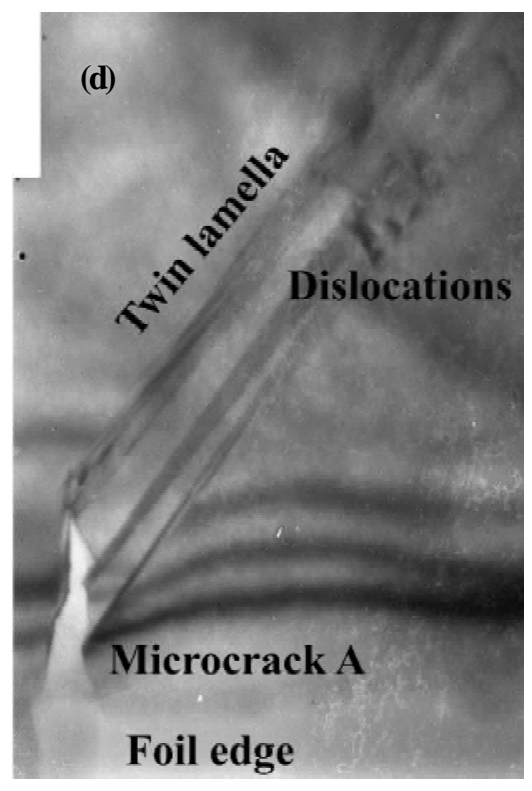

Fig. 15. Cracks (length $\sim 0.1 \mu \mathrm{m}$ ) with twin lamellas in the sole direction in iridium thin foil: a - bright field image; b - dark field image; $\mathrm{c}$ - dislocations in twin lamella A; $\mathrm{d}$-crack A at high magnification. (b)

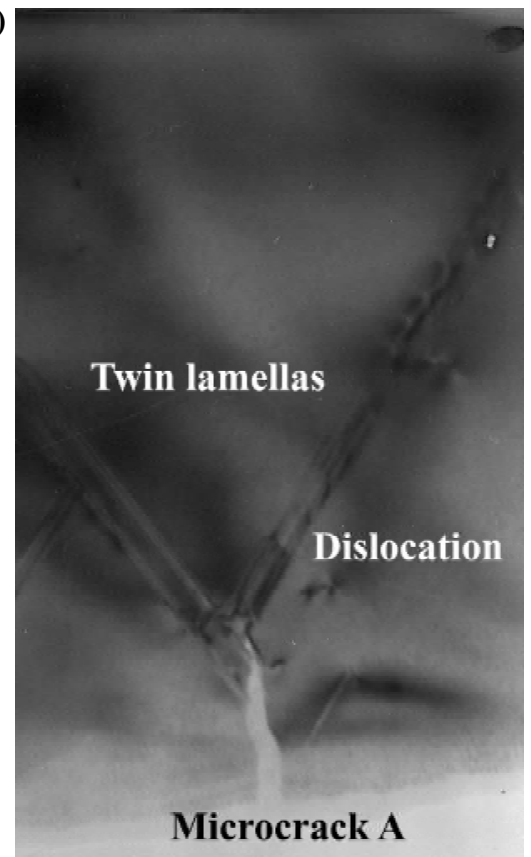

Fig. 16. Cracks (length $\sim 0.1 \mu \mathrm{m}$ ) with twin lamellas in two directions in iridium thin foil: a - bright field image; $\mathrm{b}-$ crack $\mathrm{A}$ at high magnification. 

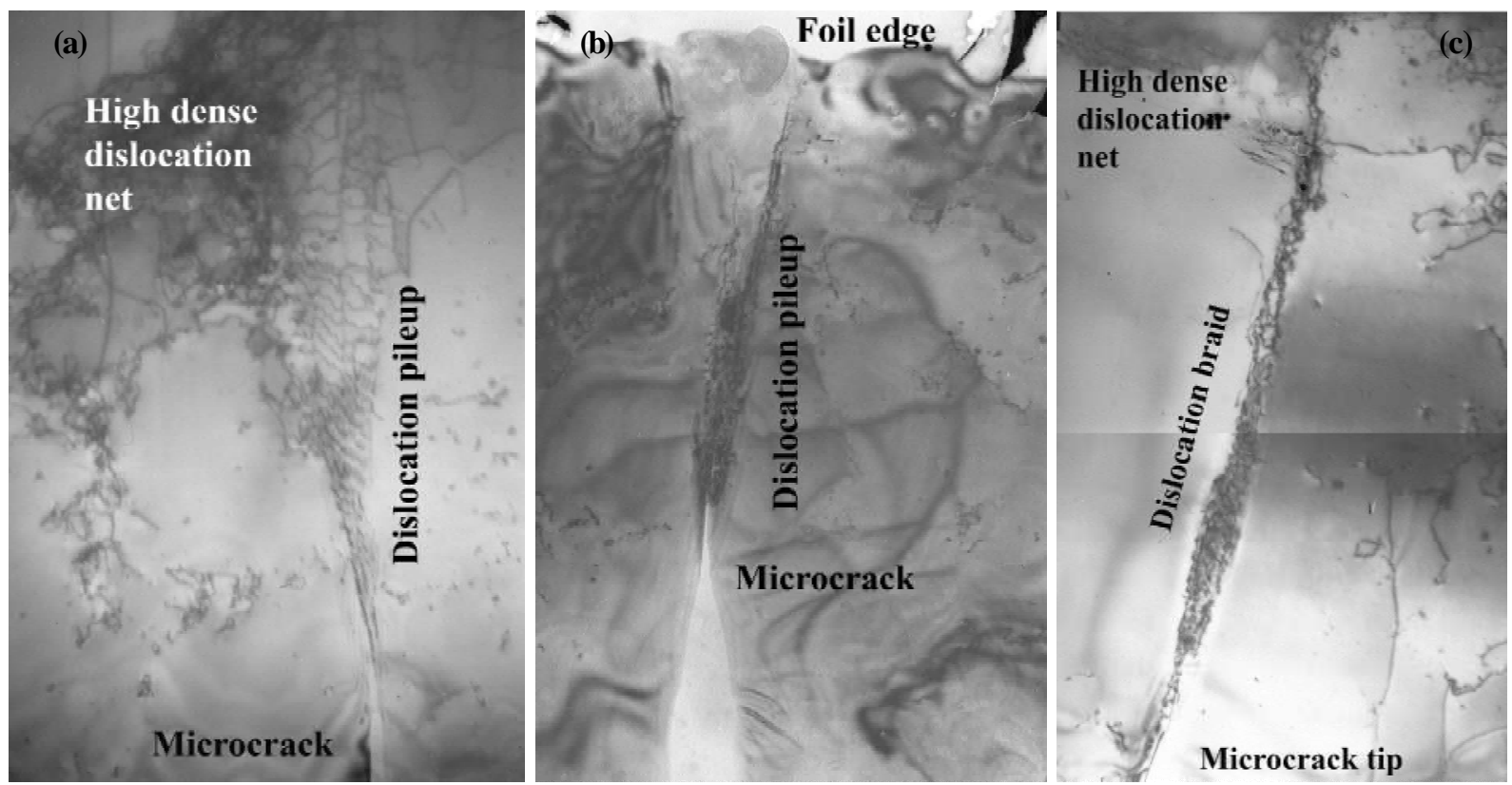

Fig. 17. Dislocation pileups ahead cracks (crack length $\sim 0.2-0.3 \mu \mathrm{m}$ ) in iridium thin foil: $\mathrm{a}-<110>$ dislocation pileup stopped on high dense net; $\mathrm{b}-<110>$ dislocation pileup stopped on the foil edge; $\mathrm{c}-<110>$ dislocation pileup stopped on the high dense net that looks like a braid.

pileups ahead the crack tips. These pileups looked like the cones or strips, where perfect dislocations are equidistantly distributed (Fig. 17a). The quantity of dislocations in the pileup was estimated as five-six dozens. As a rule, no black/white twin contrast was observed here, whereas twin spots were always detected on the diffraction pattern taken from this place. However, twin contrast appeared in the cones ahead the crack under tilting the foil on big angles. This may be considered as a support for idea that such dislocations are situated inside the twin lamella. Crystallographic analysis [44] has shown that dislocations in pileups ahead the cracks have $<110>$ Burgers vectors. In contrast with previous cases, the pileup began in vicinity of the crack tip and advanced in the depth of the foil on the distance of 2-5 $\mu \mathrm{m}$. The reason why the pileup was stopped is dislocation net which begins at the distances of 2-5 $\mu \mathrm{m}$, where iridium thin foil is practically nontransparent for $200 \mathrm{kV}$ electron beam. It should be specially noted that the TEM handbooks recommend carrying out an observation of dislocation arrangements at the same distances from the foil edges [44]. Another word, dislocation network (it is the main dislocation arrangement in iridium single crystalline thin foils at room temperature [14]) serves as the power obstacle for an advantage of the pileup in the depth of the foil. The foil edge could also play the same role (Fig. 17b). Indeed, stress fields of both objects are able to terminate the motion of dislocations [46]. Sometimes, the pileups were looked as a braid plaited from dislocations (Fig. 17c), where dislocation density reaches the highest level (up to $10^{-12}$ ). The same dislocation ar- rangements were observed in the severe deformed refractory BCC-metals, for example, molybdenum [47]. No visible changes in the geometry of top part of cracks were detected in spite of the appearance of a lot of dislocations in the vicinity of cracks.

The next set of results was obtained during in-situ tensile experiments by TEM when some cracks could grow up to the length of $0.5-2 \mu \mathrm{m}$. There were not dislocation pileups ahead the cracks tips. Single dislocations were watched in the twin lamellas, but their density was considerably lower than in the previous case (Fig. 18a). In addition, no dislocation network was observed at the electron transparent areas of the thin foil $(2-5 \mu \mathrm{m}$ from the edge), which was stretched in the TEM facility, whereas the net existed at the same distance in undeformed parts of thin foil. This finding means that the network is annihilated under tension. The same situation is inherent for FCC-metals, where $\langle 110\rangle$ dislocations possess a high mobility and, hence, dislocation network is an unstable defect arrangement $[1,46]$. It should be especially noted that any dislocation motion was observed neither near the cracks nor in the transparent areas of iridium thin foils, in contrast with other FCC-metals, where such motion is visually registered $[48,49]$. This feature may be explained by the difference between the absolute values of yield stress for refractory iridium and FCC-metals having low and middle melting points. As a result of the network annihilation, dislocations in the pileups ahead the crack obtain an opportunity to flow away from the crack tip to the deep of foil (Fig. 18a). However, if the network did not still dis- 


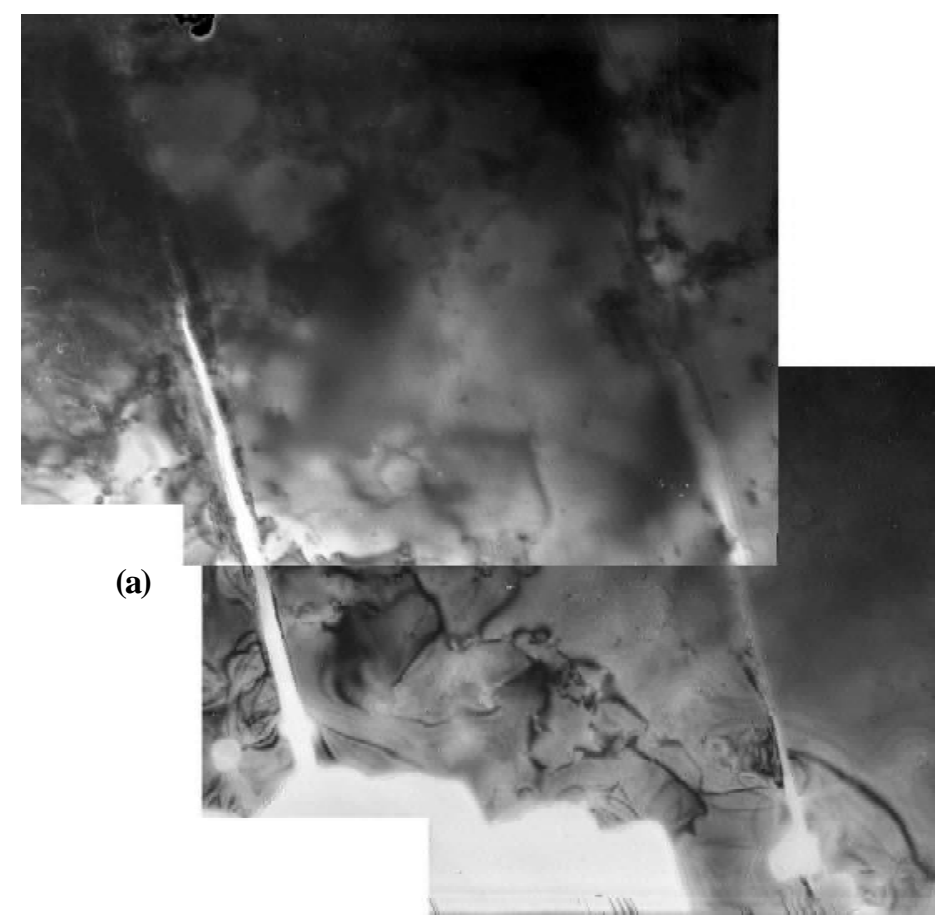

(b)
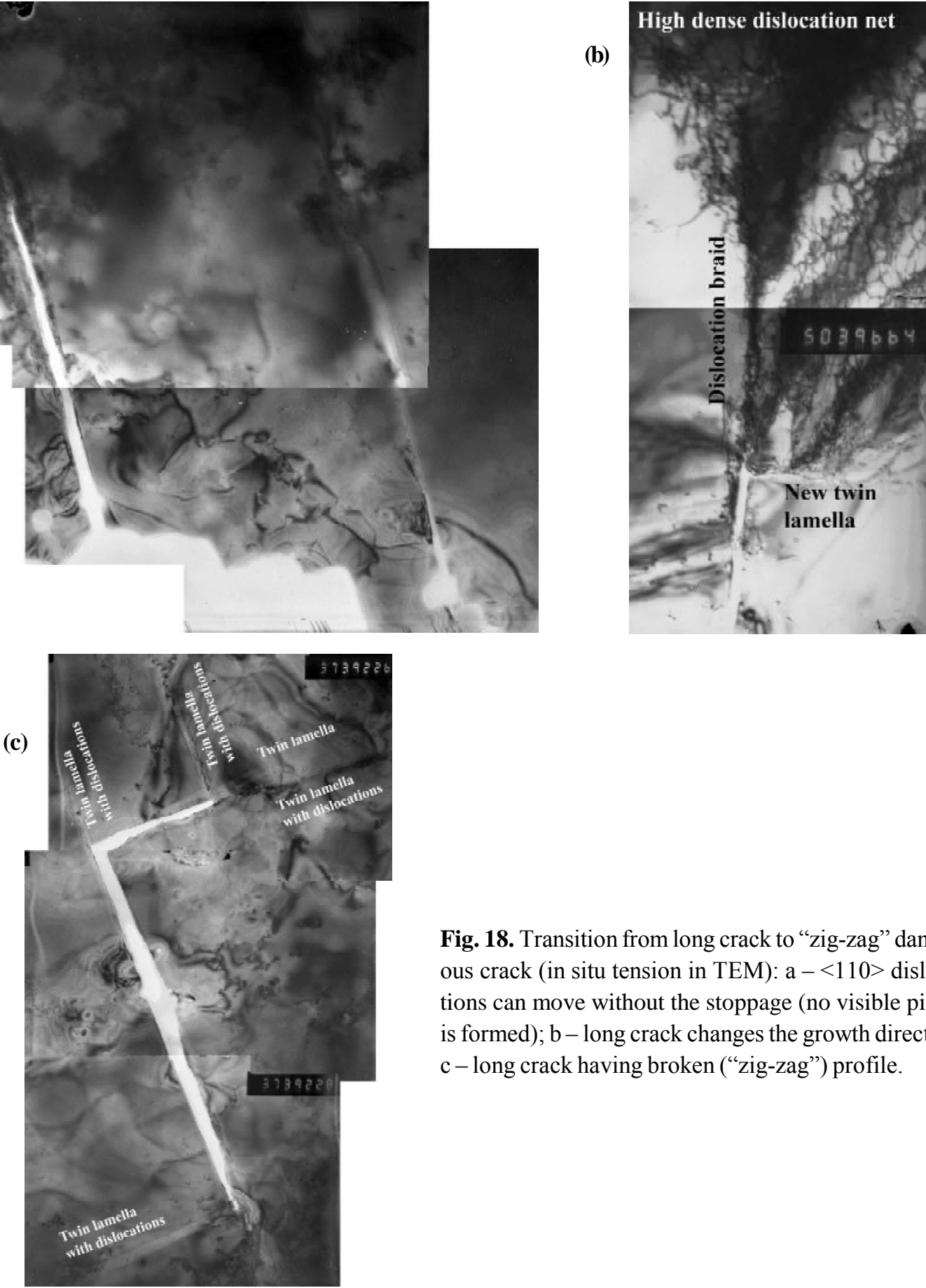

Fig. 18. Transition from long crack to "zig-zag" dangerous crack (in situ tension in TEM): a $-<110>$ dislocations can move without the stoppage (no visible pileup is formed); $\mathrm{b}$ - long crack changes the growth direction; c-long crack having broken ("zig-zag") profile.

appear, the applying of the tensile stress to the foil could lead to the following: dislocations in the pileup begin plaiting into the braid, meantime the crack changes the initial growth direction (see crack B in Fig. 18b). Such process could repeat few times and the straight crack obtains the broken or zig-zag profile (Fig. 18c). The further stretching of the foil causes an appearance of dangerous zig-zag cracks whose motion leads to the separation of the foil. This process was described in detail for FCC-metals by many researchers [48-50]. For comparison with well-known results, the fragment of dangerous crack in iridium thin foils is given in Fig. 19a and the dislocations that have a tendency to move from the crack edge into the deep of foil is shown in Fig. 19b, as well.

\section{THE CAUSE OF CLEAVAGE IN IRIDIUM}

The data presented above allow reconstructing the mechanistic picture of crack propagation at the microscopic level and at the nano-scale in iridium single crystals, whose fracture mode is BTF despite considerable elongation. In addition, TEM study of cracks in iridium 
(a)

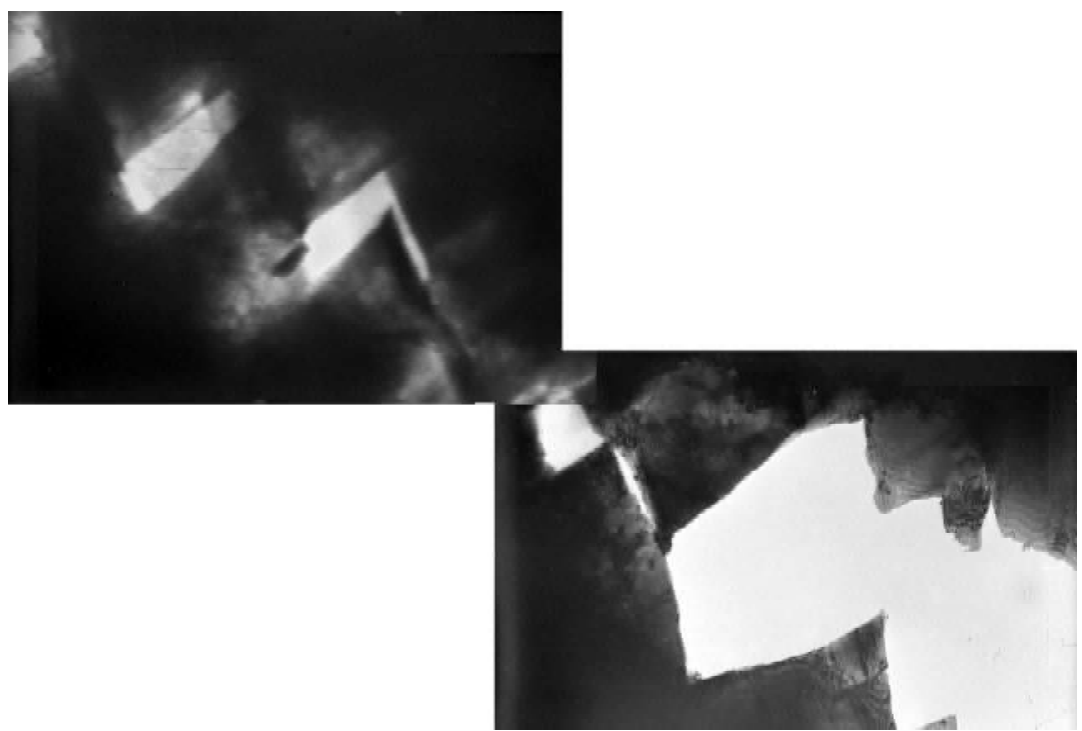

(b)

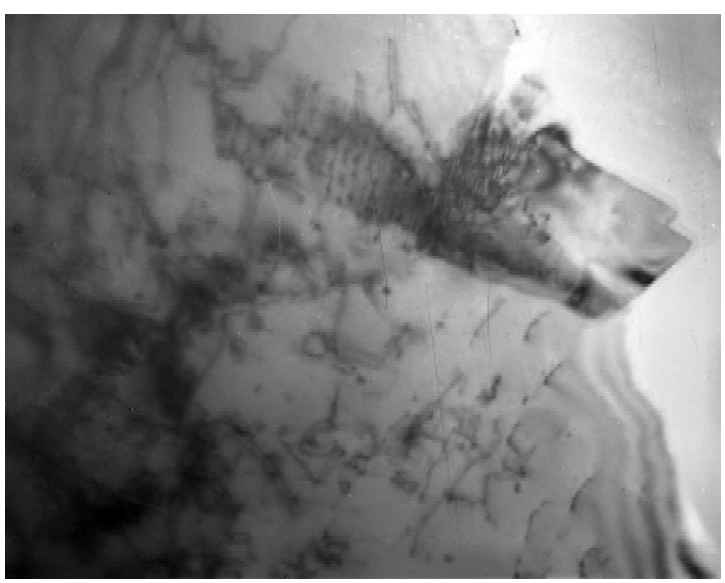

Fig. 19. Dangerous crack in iridium thin foil (in situ tension in TEM): a - fragment of zig-zag dangerous crack; $\mathrm{b}$ - edge of the zig-zag dangerous crack.

thin foils covers the transition from nano- to microscopic level. On the microscopic level in the bulk iridium single crystals the picture looks like as follows. At the beginning, tiny cracks appear and grow up to $0.03 \mathrm{~mm}$, when their propagation is terminated. At this moment, the samples exhibit the elongation 3\%-5\%, which may be estimated as considerable for intrinsically brittle crystal. The shape of these cracks (thin straight line with $\mathrm{ACO} \sim 1^{\circ}$ is like a needle) gives the basis for conclusion that they are the brittle/cleavage cracks. Further, applied tensile stress leads to the enlargement of ACO up to $10-15^{\circ}$, whereas the crack length continues to be the same. The next step is appearance of the new $0.03 \mathrm{~mm}$ tiny crack with small ACO at the tip of existed $0.03 \mathrm{~mm}$ crack having ACO $\sim 10-15^{\circ}$. As a result, the sum crack length becomes $0.06 \mathrm{~mm}$. After that, the ACO of new crack is increasing up to $10-15^{\circ}$ without crack length enlargement. Deformation tracks, which were attested as the octahedral slip bands, appear near the edges of such cracks. Both crack trajectory and geometry of deformation tracks near the cracks depend on crystallography of iridium single crystalline samples, geometry of applied load and meets empirical knowledge on plastic deformation and cleavage in FCC lattice as well [2,3,43]. This cycle can repeat few times. The long/dangerous cracks, whose length is compatible with the width of the sample, begin propagating in the "autocatalytic" regime, what is the attribute of the brittle fracture [1,3]. An absence of deformation tracks near the upper parts of such cracks may be considered as the evidence for this supposition. Under bending, ACO never grows up, deformation tracks do not appear near crack edges and the width of the bottom part increases in the dangerous cracks only.

An evolution of the notches in a FCC-metal under tension and bending may be also characterized in brief. The notching of undeformed samples induces a local plasticity of crystal in vicinity of the notches. Applying of an external stress causes the development of deformation processes near the notches, whose geometry depends on both crystallography of the sample, deformation scheme, and local stress distribution. The notch 
width/the angle under notch tip either increase (tension) or continue to be the same (bending), whereas their length never grows up under load. The notch could be the place, where plastic deformation are localized (neck is forming) and ductile dangerous crack appears, but this mechanism $[2,3]$ is not similar to the crack propagation in iridium single crystals.

Comparison of the findings on cracking in iridium single crystals and evolution of notches in monocrystalline aluminum allows concluding that the cleavage cracks in iridium could behave as either a crack in a brittle substance or a notch in a plastic FCC-metal. At the initial stage of propagation, they are brittle cracks, which appears in the preliminary deformed material at the places, where stress concentration, including tensile/shear stress, reaches the maximal level in the sample (on the edges or the notch tips). Hence, it is logically supposed that material in vicinity of the crack has lost the ability to plastic deformation during preliminary deformation and brittle crack propagation is the main channel for relaxation of elastic energy. Further, the growth of the crack in length is stopped, while its ACO begins increasing. Under tension, this process is accompanied by the appearance of the octahedral slip bands near the crack coasts when the crack length is $n \times 0.03 \mathrm{~mm}(n>2)$, whereas it does not occur under bending. It may be called the notch-like behavior. Sensitivity of the octahedral slip to the size of notch is a well-known feature of plastic deformation in FCC-metals [2]. Perhaps, plasticity due to the octahedral slip is the dominant channel for stress accommodation in this case. However, brittle crack growth starts once again as soon as resource of plasticity in material is exhausted. An absence of attributes of ductile fracture on the fracture surfaces of iridium single crystals [51] may be considered as the proof for this supposition. Presented results clearly reflect the dual nature of mechanical behavior of iridium single crystal under tension: it is really the high plastic cleavable crystal.

TEM study of cracks in iridium thin foils supports this conclusion. All cracks in iridium thin foils with the lengths of $10 \mathrm{~nm}-1 \mu \mathrm{m}$ possess a straight profile and always join with lamellas, which contain dislocations. Both power of black/white strip contrast in lamellas, splitting/twinning of spots on the electron diffraction and the quantity of dislocations inside lamellas depend on the length of crack. The more probable mechanism for appearance of the dislocations in lamellas is their generating at the tip area of crack, whose size is $\sim 1-50$ $\mathrm{nm}$, whereas the cause of their motion from crack into the foil is the field of elastic stress around the crack $[49,52]$. The elastic stress near the foil edge should be also taken into account as important additional factor. It meets the idea that the birth of dislocations is a property of the lattice models, while their motion should be considered in the frames of the mechanics of solid [53]. Appearance of dislocations and their motion never lead to visible crack tip blunting for such cracks. In vicinity of the foil edge, emitted dislocations could move inside the twin lamellas only. The dislocation network or other power barrier like another foil edge is terminating their motion when they leave the twins. As a result, dislocation pileups, whose characteristics depend on the number of emitted dislocation, are formed ahead the cracks. Annihilation of the net in vicinity of the foil edge leads to the disappearance of stable dislocation pileups ahead the cracks and cracks continue their development. They obtain the broken profile and begin advancing like the dangerous crack in thin foils of normal FCCmetals [48-50].

The mechanistic picture of cracks evolution in thin foils including dislocation emission from crack tip is described in details for nickel [49]. Comparison of these findings with iridium points to the following distinctions. The first one is the sizes of cracks and twin lamellas, which are few micrometers and few dozens of micrometers, respectively. The cracks in other normal FCCmetals have the same dimensions [25,52]. It is also important to note that the long straight cracks in iridium thin foils ( $\sim \mu \mathrm{m}$ in length) are similar to cracks in thin foils of a normal FCC-metal (see Fig. 5a). It seems to be that the highest resistance of iridium to corrosion and its big atomic weight cause this difference: the electron transparent area in iridium thin foils is extremely narrow (the usual working magnification is $30000-50000$ ). The second difference is connected with dislocation nets, which are always present in iridium thin foils and absent in other FCC-metals. Indeed, pileups of dislocations, which were emitted from cracks, in iridium thin foils are looked unique. However, this difference vanishes as soon as the net is annihilated under external stress. Another word, a crack in thin foil of iridium single crystal behaves like a crack in thin foil of a normal FCC-metal (they both emit dislocations, which have a tendency to move into the depth). Thus, some external factor (dislocation net) can influence behavior of a crack in iridium thin foil at least on the middle stage of its evolution.

Before the conclusion on the source of cleavage in iridium single crystals will be done, the modern level of the study of the iridium problem should be described in brief. The first of all, the high technological level in refining and metallurgy of iridium reached in 60-80th years is not lost. The massive iridium single crystals are successfully grown by the mean of the zone melting by the electron beam $[54,55]$. It means that the new party elaborated the effective technology for the processing irid- 
ium. This achievement allows them repeating the findings obtained in 60-90th years by the research teams from UK, USA, Germany, Russia, and Japan [56-59].

Obtained results do not allow supposing the mechanism of cleavage crack growth in the bulk iridium single crystals, which describes the relationship between crack tip geometry and dislocation emission [19-22]. However, they clearly point to the unique feature of iridium single crystal, whose thin foils differ from other FCC-metals. In contrast with a normal FCC-metal, the stable dislocation network, whose density could reach considerable value, is the main dislocations arrangement in iridium single crystals at room temperature. Due to this feature, monocrystalline iridium exhibits considerable elongation without necking at room temperature [14]. It is possible that the stable dislocation net, which possesses an ability to block a dislocation motion under external stress and, as a result, the exhaustment of plasticity, is the cause of cleavage in this the sole refractory FCCmetal in the Earth.

\section{ACKNOWLEDGEMENTS}

The author would like to thank Dr. Alexander Yermakov and Dr. Yuri N. Gornostyrev for fruitful discussions. The Russian Science Foundation (\#18-19-00217) supported this research.

\section{REFERENCES}

[1] J.F. Knott, Fundamentals of fracture mechanics, Butterworths, London, 1973. http:// www.gruppofrattura.it/sito/en/risorseesterne-2/ books/books-2

[2] R.W.K. Honeycombe, The plastic deformation of metals, Edward Arnold, London, 1968. HTTPS:// OPENLIBRARY.ORG/BOOKS/OL5665591M/ THE_PLASTIC_DEFORMATION_OF_METALS

[3] T. Yokobori, An interdisciplinary approach to fracture and strength of solids, WoltersNoordhoff Scientific Publications, Groningen, 1971.

[4] R.W. Douglass, A. Krier, and R.I. Jaffee, Battelle Memorial Institute Report NP-10939, Aug. 1961.

[5] C.A. Brookes, J.H. Greenwood, and J.L. Routbort, Brittle fracture in iridium single ńrystals, J. Appl. Phys., 1968, vol. 39, no. 5, pp. 2391-2395. https:// doi.org/10.1063/1.1656565

[6] R.E. MacFarlane, J.A. Rayne, and C.K. Jones, Temperature dependence of elastic moduli of iridium, Phys. Lett., 1966, vol. 20, no. 2, pp. $234-$ 235. https://doi.org/10.1016/0031-9163(66)90340-4

[7] R.A. Adamesku, V.A. Barkhatov, and A.V. Yermakov, Elastic properties of iridium single crystals, Vysokochistye Veschestva, 1990, vol. 3, pp. 219-220, In Russian.

[8] S. Crampin, K. Hampel, D.D. Vvedensky, and J.M. MacLaren, The calculation of stacking fault energies in close-packed metals, J. Mater. Res., 1990, vol. 5, no.10, pp. 2107 -2119. DOI: https:// doi.org/10.1557/JMR.1990.2107

[9] C.N. Reid and J.L. Routbort, Malleability and plastic anisotropy of iridium and copper, Metall. Trans., 1972, vol. 3, no. 9, pp. 2257 - 2260. https:// doi.org/10.1007/BF02643240

[10] S.S. Hecker, D.L. Rohr, and D.F. Stein, Brittle fracture in iridium, Metall. Trans., 1978, vol. 9A, no. 4, pp. 481 - 488. https://doi.org/10.1007/ BF02646403

[11] C. Gandhi and M.F. Ashby, Fracture-mechanisms maps for materials, which cleave: f.c.c., b.c.c. and h.c.p. metals and ceramics, Acta Metall., 1979, vol. 27, no. 9, pp. 1565 - 1602. https:// doi.org/10.1016/0001-6160(79)90042-7

[12] J.R. Rice, Dislocation nucleation from a crack tip: an analysis based on the Peierls concept, J. Mech. Phys. Solids, 1992, vol. 40, pp. 239-271. https://doi.org/10.1016/S0022-5096(05)80012-2

[13] P. Panfilov, A. Yermakov, V. Dmitriev, and N. Timofeev, Plastic flow of iridium, Platinum Metals Rev., 1991, vol. 35, no. 4, pp. 196-200. http://citeseerx.ist.psu.edu/viewdoc/ summary?doi=10.1.1.564.9630

[14] P. Panfilov, Deformation tracks distribution in iridium single crystals under tension, J. Mater. Sci., 2007, vol. 42, pp. 8230-8235. DOI: $10.1007 /$ s10853-007-1722-7

[15] N.I. Timofeev, A.V. Yermakov, A.V. Dmitriev, and P.E. Panfilov, Metallurgy and mechanical behavior of iridium, Urals Branch of Russian Academy of Science, Ekaterinburg, 1996.

[16] A.V. Yermakov, M.S. Igumnov, and P.E. Panfilov, Iridium: technology and applications, Lambert Academic Publishing, Saarbruken, 2015.

[17] S.P. Lynch, Environmentally assisted cracking: overview of evidence for an adsorption-induced localized-slip process, Acta Metall., 1988, vol. 36, no. 10, pp. 2639 - 2661. https://doi.org/10.1016/ 0001-6160(88)90113-7

[18] S.P. Lynch, Ductile and brittle crack growth: fractography, mechanisms and criteria, Materials Forum, 1988, vol. 11, pp. 268 - 283.

[19] J.R. Rice and R. Thomson, Ductile versus brittle behaviour of crystals, Phil. Mag., 1974, vol. 29, pp. 73-97. https://doi.org/10.1080/ 14786437408213555 
[20] I.-H. Lin and R. Thomson, Cleavage, dislocation emission, and shielding for cracks under general loading, Acta Metall., 1986, vol. 34, no. 2, pp. 187-206. https://doi.org/10.1016/00016160(86)90191-4

[21] A.S. Argon, Brittle to ductile transition in cleavage fracture, Acta Metall., 1987, vol. 35, no. 2, pp. 185-196. https://doi.org/10.1016/00016160(87)90228-8

[22] M.L. Jokl, V. Vitek, C.J. McMahon, and P. Burgers, On the micromechanics of brittle fracture: existing vs injected cracks, Acta Metall., 1989, vol. 37, no. 1, pp. 87-97. https://doi.org/10.1016/ 0001-6160(89)90269-1

[23] S.P. Lynch, Concerning the anomalous brittle fracture behaviour of iridium, Scripta Materialia, 2007, vol. 57, no. 2, pp. 85-88. DOI: 10.1016/ j.scriptamat.2007.03.039

[24] P. Panfilov, A. Yermakov, and G. Baturin, The cause of cleavage in iridium single crystals, J. Mater. Sci. Lett., 1990, vol. 9, no. 10, pp. 11621164. DOI: 10.1007/BF0072187

[25] P. Panfilov, V. Novgorodov, and G. Baturin, An evolution of microcracks in thin foil of facecentred cubic metal, J. Mater. Sci. Lett., 1992, vol. 11, no. 4, pp. 229-232. https://doi.org/10.1007/ BF00741429

[26] F.D. Richardson, Iridium as high temperature material, Platinum Metals Rev., 1958, vol. 2, no. 3, pp.83 - 85. https://www.ingentaconnect.com/ content/matthey/pmr/1958/00000002/00000003/ art00003?crawler=true

[27] J.R. Handley, Increasing application for iridium, Platinum Metals Rev., 1986, vol. 30, no. 1, pp. 12 - 13. https://www.technology.matthey.com/ article/30/1/12-13/

[28] L.B. Hunt, A history of iridium, Platinum Metals Rev., 1987, vol. 31, no. 1, pp. 32-41. https:// www.technology.matthey.com/article/31/1/32-41/

[29] E.A. Franko-Ferreira, G.M. Goodwin, T.G. George, and G.H. Rinehart, Long life radioisotopic sources encapsulated in platinum metal alloys, Platinum Metals Rev., 1997, vol. 41, no. 4, pp. 154 - 163. https://www.technology.matthey.com/ article/41/4/154-163/\#

[30] E. K. Ohriner, Processing of Iridium and Iridium Alloys, Platinum Metals Rev., 2008, vol. 52, no. 3, pp. 186-197. doi:10.1595/147106708x333827

[31] J.D. Ragaini, Iridium refining, In: Iridium. Proceedings of the International symposium Sponsored by the SMD division of the Minerals, Metals \& Materials Society (TMS) Held During the 2000 TMS Annual Meeting in Nashville,
Tennessee, March 12-16, 2000, ed. by Evan K. Ohriner, Richard D. Lanam, Peter Panfilov, and Hiroshi Harada, Publication of TMS, USA, 2000, pp. 333-338.

[32] D.L. Rohr, L.E. Murr, and S.S. Hecker, Brittle fracture in polycrystalline Ir-0.3 pct W, Metall. Trans., 1979, vol. 10A, no. 4, pp. 399-405. https:/ /doi.org/10.1007/BF02697065

[33] B.L. Mordike and C.A. Brookes, The tensile properties of iridium at high temperatures, Platinum Metals Rev., 1960, vol. 4, no. 3, pp. 94 - 99. https://www.technology.matthey.com/ article/4/3/94-99/

[34] R.W. Douglass and R.I. Jaffee, Elevatedtemperature properties of rhodium, iridium and ruthenium, Proc. ASTM., 1962, vol. 62, pp. $627-637$.

[35] G. Reinacher, Beitrag zur kurzzeitstandfestigkeit von platinmetallen. VI. Iridium, Metall., 1964, vol. 18 , no. 7 , pp. $731-836$.

[36] C.T. Liu, H. Inouye, and A.C. Schaffhauser, Effect of thorium additions on metallurgical and mechanical properties of $\mathrm{Ir}+0.3 \mathrm{pc} t \mathrm{~W}$ alloys, Metall. Trans., 1981, vol. 12A., no. 6, pp. 993 - 1002. https://doi.org/10.1007/BF02643480

[37] P. Panfilov, V. Novgorodov, and A. Yermakov, Fracture behaviour of polycrystalline iridium under tension in the temperature range 20-1500 ${ }^{\circ} \mathrm{C}$, J. Mater. Sci. Lett., 1994, vol. 13, no. 2, pp. 137-141. https://doi.org/10.1007/BF00416826

[38] P. Panfilov, On the inherent fracture mode of iridium at room temperature, J. Mater. Sci., 2005, vol. 40, no. 22, pp. 5983-5987. https://doi.org/ 10.1007/s10853-005-1296-1

[39] H. Hieber, B.L. Mordike, and P. Haasen, Deformation of zone-melted iridium single crystals, Platinum Metals Rev., 1964, vol. 8, no. 3, pp. 102 - 106. https://www.technology. matthey.com/article/8/3/102-106/

[40] P. Haasen, H. Hieber, and B.L. Mordike, Die plastische verformung von iridium einkristallen, Zt. Metallkde, 1965, vol. 56, no. 12, pp. $832-841$.

[41] A. Yermakov, P. Panfilov, and R. Adamesku, The main features of plastic deformation of iridium single crystals, J. Mater. Sci. Lett., 1990, vol. 9, no. 6, pp. 696-697. https://doi.org/10.1007/ BF00721807

[42] P. Panfilov, A. Yermakov, O.V. Antonova, and V.P. Pilyugin, Plastic Deformation of Polycrystalline Iridium at Room Temperature, Platinum Metals Rev., 2009, vol. 53, no. 3, pp. 138-146. doi:10.1595/ 147106709x463318 
[43] A. Kelly and G.W. Groves, Crystallography and crystal defects, Longman, London, 1970.

[44] P.B. Hirsch, A. Howie, R.B. Nicholson, D.W. Pashley, and M.J. Whelan, Electron Microscopy of Thin Crystals, Butterworths, London, 1965.

[45] B.R. Lawn, Physics of Fracture, J. Am. Ceram. Soc., 1983, vol. 66. No. 2, pp. 83-91. https:// doi.org/10.1111/j.1151-2916.1983.tb09980.x

[46] J.P. Hirth and J. Lote, Theory of Dislocations, McGrow-Hill, New York, 1968.

[47] V.V. Rybin, Severe Plastic Deformation and Fracture of Metals, Metallurgia, Moscow, 1986.

[48] R.L. Lyles and H.G.F. Wilsdorf, Microcrack nucleation and fracture in silver crystals, Acta Metall., 1975, vol. 23, no. 2, pp. 269-277. https:// doi.org/10.1016/0001-6160(75)90192-3

[49] I.M. Robertson and H.K. Birnbaum, An HVEM study of hydrogen effects on the deformation and fracture of nickel, Acta Metall., 1986, vol. 34, no. 3, pp. 353-366. https://doi.org/10.1016/00016160(86)90071-4

[50] H.G.F. Wilsdorf, The role of glide and twinning in the final separation of ruptured gold crystals, Acta Metall., 1982, vol. 30, no.6, pp. 1247-1258. https://doi.org/10.1016/0001-6160(82)90021-9

[51] P. Panfilov and A. Yermakov, On brittle fracture in polycrystalline iridium, J. Mater. Sci., 2004, vol. 39, no. 14, pp. 4543-4552. https://doi.org/ 10.1023/B:JMSC.0000034148.03387.71

[52] S.M. Ohr, An electron-microscopy study of crack tip deformation and its impact on the dislocation theory of fracture, Mater. Sci. Eng., 1985, vol. 72, no. 1, pp. 1-35. https://doi.org/ 10.1016/0025-5416(85)90064-3

[53] S.M. Ohr, Dislocation-crack interaction, J. Phys. Chem. Solids, 1987, vol. 48, no. 11, pp. 1007-1014. https://doi.org/10.1016/0022-3697(87)90116-8
[54] J. Yang, H. Wang, B. Wang, R. Hu, Y. Liu, and $\mathrm{X}$. Luo, Numerical and experimental study of electron beam floating zone melting of Iridium single crystal, Journal of Materials Processing Tech., 2017, vol. 250, pp. 239-246. http:// dx.doi.org/10.1016/j.jmatprotec.2017.07.016

[55] B. Wang, S. Li, Y. Wang, H. Zhong, R. Hua, Y. Liu, and X. Luo, Single-crystal growth of iridium with [100] and [110] orientations by electron beam zone melting, Vacuum, 2018, vol. 154, pp. 141-147. https://doi.org/10.1016/ j.vacuum.2018.05.009

[56] P. Wang, J. Yu, X. Zhou, and J. Chen, Research Progress on Brittleness of Iridium, Rare Metal Materials and Engineering, 2015, vol. 44, no. 10, pp. 2363-2367. https://doi.org/10.1016/S18755372(16)30021-2

[57] M. Scapin, L. Peroni, C. Torregrosa, A. PerilloMarcone, M. Calviani, L. Gomez-Pereira, F. Leaux, and M. Meyer, Experimental results and strength model identification of pure iridium, International Journal of Impact Engineering, 2017, vol. 106, pp. 191-201. http://dx.doi.org/10.1016/ j.ijimpeng.2017.03.019

[58] J. Yang, H. Wang, R. Hu, S. Li, Y. Liu, and X. Luo, Anomalous Tensile Strength and Fracture Behavior of Polycrystalline Iridium from Room Temperature to $1600^{\circ} \mathrm{C}$, Adv. Eng. Mater., 2018, vol. 20, no. 7, pp. 1701114. https://doi.org/ 10.1002/adem.201701114.

[59] J. Yang, H. Wang, R. Hu, F. Zhang, S. Li, Y. Liu, and X. Luo, Atomistic Simulation of Orientationdependent Tension Deformation Behavior of Single Crystal Iridium, Rare Metal Materials and Engineering, 2019, vol. 48, pp. 1380-1385. 